\title{
Molecular modeling, quantum polarized ligand docking and structure-based 3D-QSAR analysis of the imidazole series as dual $\mathrm{AT}_{1}$ and $\mathrm{ET}_{\mathrm{A}}$ receptor antagonists
}

\author{
Khuraijam Dhanachandra SINGH, Karthikeyan MUTHUSAMY* \\ Department of Bioinformatics, Alagappa University, Karaikudi - 630 004, Tamil Nadu, India
}

\begin{abstract}
Aim: Both endothelin $\mathrm{ET}_{\mathrm{A}}$ receptor antagonists and angiotensin $\mathrm{AT}_{1}$ receptor antagonists lower blood pressure in hypertensive patients. $\mathrm{A}$ dual $\mathrm{AT}_{1}$ and $\mathrm{ET}_{\mathrm{A}}$ receptor antagonist may be more efficacious antihypertensive drug. In this study we identified the mode and mechanism of binding of imidazole series of compounds as dual $\mathrm{AT}_{1}$ and $\mathrm{ET}_{\mathrm{A}}$ receptor antagonists.

Methods: Molecular modeling approach combining quantum-polarized ligand docking (QPLD), MM/GBSA free-energy calculation and 3D-QSAR analysis was used to evaluate 24 compounds as dual $\mathrm{AT}_{1}$ and $\mathrm{ET}_{\mathrm{A}}$ receptor antagonists and to reveal their binding modes and structural basis of the inhibitory activity. Pharmacophore-based virtual screening and docking studies were performed to identify more potent dual antagonists.

Results: 3D-QSAR models of the imidazole compounds were developed from the conformer generated by QPLD, and the resulting models showed a good correlation between the predicted and experimental activity. The visualization of the 3D-QSAR model in the context of the compounds under study revealed the details of the structure-activity relationship: substitution of methoxymethyl and cyclooctanone might increase the activity against $\mathrm{AT}_{1}$ receptor, while substitution of cyclohexone and trimethylpyrrolidinone was important for the activity against $\mathrm{ET}_{\mathrm{A}}$ receptor; addition of a trimethylpyrrolidinone to compound 9 significantly reduced its activity against $\mathrm{AT}_{1}$ receptor but significantly increased its activity against $\mathrm{ET}_{\mathrm{A}}$ receptor, which was likely due to the larger size and higher intensities of the $\mathrm{H}$-bond donor and acceptor regions in the active site of $\mathrm{ET}_{\mathrm{A}}$ receptor. Pharmacophore-based virtual screening followed by subsequent Glide SP, XP, QPLD and MM/GBSA calculation identified 5 potential lead compounds that might act as dual AT $_{1}$ and $\mathrm{ET}_{\mathrm{A}}$ receptor antagonists.

Conclusion: This study may provide some insights into the development of novel potent dual $\mathrm{ET}_{\mathrm{A}}$ and $\mathrm{AT}_{1}$ receptor antagonists. As a result, five compounds are found to be the best dual antagonists against $A T_{1} R$ and $E T_{A}$ receptors.
\end{abstract}

Keywords: imidazole; $\mathrm{AT}_{1}$ receptor; $\mathrm{ET}_{\mathrm{A}}$ receptor; quantum-polarized ligand docking (QPLD); MM/GBSA free-energy calculation; 3D-QSAR; molecular dynamics simulation; antihypertensive drug

Acta Pharmacologica Sinica (2013) 34: 1592-1606; doi: 10.1038/aps.2013.129

\section{Introduction}

Hypertension is a multi-factorial trait that results from a combination of genetic and environmental factors ${ }^{[1]}$. Several candidate proteins that are linked to hypertension have been identified; among these, the angiotensin II type-1 receptor $\left(A T_{1} R\right)$ gene and endothelin receptor type $A\left(E T_{A}\right)$ are important targets for the design of antihypertensive drugs ${ }^{[2-6]}$.

Angiotensin II (Ang II) activates the $\mathrm{AT}_{1} \mathrm{R}$ on arterial smooth muscle cells; this activation causes vasoconstriction and

\footnotetext{
* To whom correspondence should be addressed.

E-mail mkbioinformatics@gmail.com

Received 2013-04-17 Accepted 2013-08-16
}

increases blood pressure ${ }^{[7]}$, and $\mathrm{AT}_{1} \mathrm{R}$ antagonists reduce blood pressure in patients with essential hypertension ${ }^{[8]}$. Endothelin I (ET-1) activates the $\mathrm{ET}_{\mathrm{A}}$ and $\mathrm{ET}_{\mathrm{B}}$ receptors; the activation of these receptors induces vascular smooth muscle cell contraction and increases blood pressure ${ }^{[9]}$, and $\mathrm{ET}_{\mathrm{A}} / \mathrm{ET}_{\mathrm{B}}$ receptor antagonists are also given to patients with essential hypertension to reduce diastolic blood pressure ${ }^{[10]}$.

There is a significant medical need for an antihypertensive drug that is effective as a monotherapy in a wide variety of patients ${ }^{[11]}$. The endogenous Ang II and ET-1 proteins are powerful vasoconstrictors and mitogens, and the pathogenesis of hypertension and cardiovascular disease is associated with both of these factors ${ }^{[11]}$. Elevated levels of Ang II pro- 
mote the synthesis and vasoconstrictive action of ET-1, and elevated levels of ET-1 increase the synthesis and vasoconstrictive action of Ang II; therefore, these factors constitute a positive dual-feedback mechanism and an excellent target for hypertension management ${ }^{[11]}$. Because Ang II and ET-1 cause increases in blood pressure and promote each other's actions, it is plausible that the concomitant blockade of both the angiotensin and endothelin endocrine/paracrine pathways may lead to enhanced reductions in blood pressure ${ }^{[12-14]}$. The dual inhibition of both $\mathrm{AT}_{1} \mathrm{R}$ and $\mathrm{ET}_{\mathrm{A}}$ has more physiological benefit than the individual inhibition of either $\mathrm{AT}_{1} \mathrm{R}$ or $\mathrm{ET}_{\mathrm{A}}$ alone, as demonstrated in hypertensive transgenic rats that overexpress the human renin gene ${ }^{[12]}$.

In this study, combined homology modeling, molecular dynamics simulation, MM/GBSA free-energy calculations and atom-based 3D-QSAR analysis were performed to identify the mode and mechanism of binding of the imidazole series of compounds ${ }^{[15]}$ as dual inhibitors of $\mathrm{AT}_{1} \mathrm{R}$ and $\mathrm{ET}_{\mathrm{A}}$. In this paper, we describe a robust combined ligand- and structurebased development of 3D-QSAR and utilize this approach to examine the mechanism of dual inhibition of $A T_{1} R$ and $E_{A}$. The contours generated from QSAR studies highlight the structural features required for dual inhibition, and it will be useful for further design of more potent inhibitors.

\section{Materials and methods}

\section{Homology modeling of $\mathrm{ET}_{\mathrm{A}}$}

The sequence of the human $\mathrm{ET}_{\mathrm{A}}$ (427 residues) was retrieved from the UniProt database (accession number: P25101). The crystal structures of human $\beta_{2}$ Adrenergic Receptor (3KJ6) and Adenosine $\mathrm{A}_{2 \mathrm{~A}}$ Receptor $(3 \mathrm{PWH})$ were retrieved from the Protein Data Bank (PDB) and selected as templates for homology modeling according to the result of a BLAST search. The templates were selected based on sequence identity and the coverage of the sequence. The sequences of $\mathrm{ET}_{\mathrm{A}}$ and the templates (3PWH and 3KJ6) were aligned using ClustalW (http:/ / www. ichec.ie/infrastructure/software/GlustalW) ${ }^{[16]}$. A BLOSSUM scoring matrix was used for the ClustalW alignment ${ }^{[17]}$. Because the sequence identity of the target and template sequence is $<30 \%$, we chose a multiple template approach; this increased the coverage of the sequence alignment. Many studies have reported that using multiple templates improves the quality of homology modeling ${ }^{[18-20]}$. Fanelli and Benedetti reported that the selection of the proper template by careful sequence comparisons is a crucial step in comparative modeling ${ }^{[21]}$. The $\mathrm{ET}_{\mathrm{A}}$ tertiary structure was modeled using modeller 9.10 software (Accelrys Inc, San Diego, CA, USA) ${ }^{[22-25]}$.

\section{Refinement and validation of the model}

To obtain a reliable model, structural refinement was performed using stepwise constrained optimization ${ }^{[26]}$. First, the initial models were optimized and energy was minimized to correct disallowed torsion angles and to eliminate unfavorable atom-atom contacts using Prime 2.0 ${ }^{[27]}$ software (Schrodinger, LLC, New York, NY, USA) ${ }^{[28]}$. The validation of the modeled structures was performed by inspecting the psi/phi Ramach- andran plot obtained from PROCHECK analysis ${ }^{[2]}$.

\section{Molecular dynamics simulation}

Molecular dynamics (MD) simulations were carried out for the modeled $\mathrm{ET}_{\mathrm{A}}$ protein and the theoretical $\mathrm{AT}_{1} \mathrm{R}$ protein $(\mathrm{PDB}$ ID: 1ZV0) ${ }^{[30]}$ from the Protein Data Bank (www.rcsb.org) using Desmond MD code and the OPLS-AA 2005 (Optimized Potentials for Liquid Simulations-All Atom) force field ${ }^{[31-32]}$ for minimization of the system. Using the Desmond system builder, a $10 \AA$ buffered orthorhombic system with periodic boundary conditions was constructed using a DPPC lipid membrane ${ }^{[33-35]}$ and a TIP4P explicit water solvent ${ }^{[36]}$. The overall charge was neutralized by $0.15 \mathrm{~mol} / \mathrm{L} \mathrm{NaCl}$. The simulations were performed in the NPT ensemble. The temperature of $325^{\circ} \mathrm{K}$ and pressure of 1.013 bar were kept constant by coupling the system to a Berendsen thermostat and barostat. An integration step of 2.0 was used, Coulombic interactions were calculated using a cutoff radius of $9.0 \AA$, and long-range electrostatic interactions were calculated using the smooth particle mesh Ewald method $^{[37]}$. Before each MD simulation, a default Desmond membrane protein relaxation protocol was applied ${ }^{[38]}$.

\section{Preparation of protein}

The starting coordinates of the $\mathrm{AT}_{1} \mathrm{R}$ and modeled $\mathrm{ET}_{\mathrm{A}}$ protein were further modified for Glide docking calculations and subjected to protein preparation using the protein preparation wizard of Glide software (Schrodinger, LLC, New York, NY, USA $)^{[39]}$. For these calculations, the proteins were minimized using the Protein Preparation Wizard by applying an OPLS2005 force field. Progressively weaker restraints were applied to the non-hydrogen atoms. This refinement procedure was carried out based on the recommendations of Schrodinger LLC (New York, NY, USA). Because Glide uses the full OPLS2005 force field at an intermediate docking stage and claims to be more sensitive to geometric details than other docking tools. The most likely positions of hydroxyl and thiol hydrogen atoms, protonation states and tautomers of His residues, and Chi 'flip' assignments for Asn, Gln and His residues were selected. Progressive minimizations were performed until the average root mean square deviation of the non-hydrogen atoms reached $0.3 \AA$.

\section{Active site predictions}

The active sites of the modeled $\mathrm{ET}_{\mathrm{A}}$ protein and $\mathrm{AT}_{1} \mathrm{R}$ were investigated using the SiteMap program (Schrodinger, LLC, New York, NY, USA) ${ }^{[40]}$. This software generates information on the binding site's characteristics using novel search and analytical facilities; a SiteMap calculation begins with an initial search step that identifies or characterizes one or more regions on the protein surface that may be suitable for binding ligands to the receptor using grid points.

\section{Ligand preparation}

Twenty-four compounds that have been reported to be dual inhibitors of $\mathrm{AT}_{1} \mathrm{R}$ and $\mathrm{ET}_{\mathrm{A}}{ }^{[15]}$ were drawn in Maestro (Schrodinger, LLC, New York, NY, USA). Each structure was 
assigned an appropriate bond order using the LigPrep package from Schrodinger, LLC, New York, NY, USA ${ }^{[4]]}$. The inhibitors were converted to mae format (Maestro, Schrodinger, LLC, New York, NY, USA) and optimized by means of the Optimized Potentials for Liquid Simulations (OPLS 2005) force field using the default setting.

\section{Glide extra precision docking (XP) and QM-polarizes ligand docking (QPLD)}

All the compounds were subjected to Glide XP docking. In addition, the popular docking program Glide and QM/MM software Q-site were combined to perform a QM-Polarized Ligand Docking (QPLD) analysis ${ }^{[22,43]}$. For QM/MM calculations, this approach uses the QSITE program ${ }^{[42]}$, which is coupled with JAGUAR ${ }^{[4]}$ for the QM region and the IMPACT molecular modeling code for the MM region ${ }^{[45]}$. When there are covalent connections between the QM and MM regions, it uses frozen localized molecular orbitals along the covalent bonds to construct an interface between the two regions. The $\mathrm{QM} / \mathrm{MM}$ energy is calculated as the coulomb-van der Waals force of the complex that is calculated from the electrostatic potential energy of the ligand; this is in turn generated from a single point calculation using density functional theory for the QM region with the 6-31G*/LACVP* basis set, B3LYP density functional, and "Ultrafine" SCF accuracy level (iacc=1, iac$\mathrm{scf}=2$ ). Initially, a regular standard precision (SP) Glide docking followed by extra precision (XP) refinement was carried out, generating 5 poses per docked molecule; these were then submitted to QM-ESP charge calculation at the B3LYP/3-21G* level within the protein environment defined by the OPLS2005 force field. Finally, the resulting poses were re-docked for another Glide run using the ESP atomic charges and XP scoring modes $^{[46]}$.

\section{Computational mutagenesis studies}

Computational mutagenesis and alanine scanning studies were carried out using the Mutate Residues script from Schrodinger, LLC, New York, NY, USA. Computational mutagenesis is a technique used to determine the contribution of specific residues to the function of a protein by mutating the residues to alanine $e^{[47,48]}$ to understand the structural and energetic characteristics of the hotspots. The mutated systems were not minimized, and it was assumed that no local rearrangements occur with the mutation. The residues that interacted with BMS-248360 were mutated to alanine, and we subsequently analyzed the binding free energy.

\section{Binding free energy calculation}

Prime/MM-GBSA was used to predict the free energy of binding between the receptor and the set of ligands. The binding free energy $\left(\Delta G_{\text {bind }}\right)$ was calculated using the default parameters of Prime software, Schrodinger, LLC, New York, NY, $\mathrm{USA}^{[27,49,50]}$.

\section{D-QSAR model generation}

PHASE 3.3, implemented in the Maestro 9.2 software pack- age (Schrodinger, LLC, New York, NY, USA) ${ }^{[51,52]}$, was used to generate the 3D-QSAR models of the imidazole series as dual inhibitors of $\mathrm{AT}_{1} \mathrm{R}$ and $\mathrm{ET}_{\mathrm{A}}$. A set of 24 imidazole compounds (Table 1) was selected from the available literature ${ }^{[10]}$ and used in the present study. The alignment was achieved using the top-ranked docking pose from Glide XP and QPLD for each inhibitor. QPLD showed a better correlation with the experimentally determined activity; we therefore used QPLDgenerated conformations to generate the 3D-QSAR models using the default parameters. In the partial least-squares (PLS) regression analysis, a leave-n-out (LNO) validation was performed. Then, non-cross validated analysis was performed to obtain the final QSAR model. PHASE provides a standard set of six pharmacophore features: hydrogen bond acceptors (A), hydrogen bond donors (D), hydrophobic groups $(\mathrm{H})$, negatively ionizable $(\mathrm{N})$, positively ionizable $(\mathrm{P})$, and aromatic ring $(\mathrm{R})^{[51]}$. In this study, we performed 3D pharmacophore screening using the two top-ranked hypothetical pharmacophores, AARRR and AARRH, representing the chemical features of dual $\mathrm{AT}_{1} \mathrm{R}$ and $\mathrm{ET}_{\mathrm{A}}$ inhibitors. Using these pharmacophores, we searched chemical databases and retrieved molecules with novel and desired chemical features from the ChemBridge database (www.ChemBridge.com). The compounds retrieved from the database were subjected to structure-based screening. Glide provides three different levels of docking precision: HTVS (high throughput virtual screening), SP (standard precision) and XP (extra precision). We carried out our calculations using HTVS first, and then used the SP and XP modes to further refine the good ligand poses. Then, finally we docked the screened compounds using the more precise docking protocol, QPLD.

\section{Enrichment studies}

The Schrodinger decoy set was used to validate the pharmacophore hypotheses, virtual screening (VS) and QPLD. This decoy set was downloaded as a 3D SD file from the Schrodinger Website and consists of 1000 drug-like compounds (with an average molecular weight of 400 Daltons) and 27 active compounds from the published literature ${ }^{[15]}$. For our validation, 100 drug-like compounds were randomly selected from the Schrodinger decoy set and mixed with 27 active molecules. QPLD calculation is a time-consuming process, so we reduced our decoy set to 127 . We used this method to evaluate the ability of our hypothetical pharmacophores and docking study to discriminate and separate the active compounds from the inactive compounds in our larger set of molecules.

\section{Results and discussion}

\section{$\mathrm{ET}_{\mathrm{A}}$ sequence alignment and model generation}

A sequence similarity search was performed using NCBI BLASTp, a conventional alignment tool for protein sequences. Sequence similarity is the main criterion for selecting a template for homology modeling. The sequence similarity between the $\mathrm{ET}_{\mathrm{A}}$ protein and other known GPCR proteins is very low $(<30 \%)$, but we selected the templates from the GPCR superfamily that had high resolution and maximum sequence 
Table 1. Compounds selected (imidazole series) for 3D-QSAR study and their measured biological activity and predicted activity.
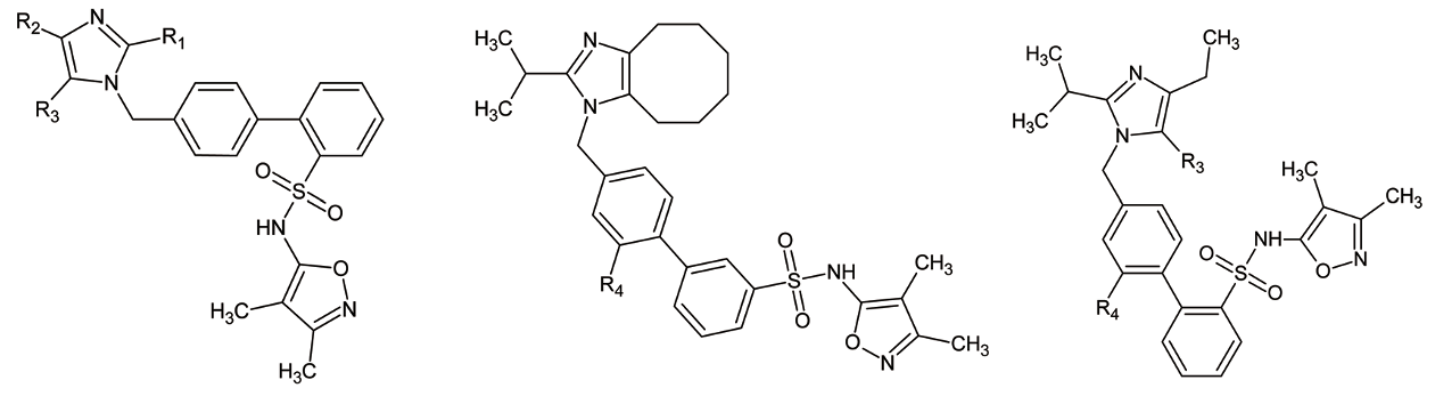

\begin{tabular}{|c|c|c|c|c|c|c|c|c|}
\hline \multicolumn{5}{|c|}{ Compound } & \multicolumn{2}{|c|}{$\mathrm{AT}_{1} \mathrm{R}$} & \multicolumn{2}{|c|}{$\mathrm{ET}_{\mathrm{A}}$} \\
\hline № & $\mathrm{R}_{1}$ & $\mathrm{R}_{2}$ & $\mathrm{R}_{3}$ & $\mathrm{R}_{4}$ & $\begin{array}{l}\text { Actual } \\
\text { activity }\end{array}$ & $\begin{array}{l}\text { Predicted } \\
\text { activity }\end{array}$ & $\begin{array}{l}\text { Actual } \\
\text { activity }\end{array}$ & $\begin{array}{c}\text { Predicted } \\
\text { activity }\end{array}$ \\
\hline 1 & $\mathrm{Bu}$ & $\mathrm{Cl}$ & $\mathrm{CONH}_{2}$ & - & 7.62 & 7.992 & 6.381 & 7.094 \\
\hline 2 & $\operatorname{Pr}$ & $\mathrm{Cl}$ & $\mathrm{CONH}_{2}$ & - & 7.678 & 8.031 & 7.398 & 7.308 \\
\hline 3 & $\operatorname{Pr}$ & Et & $\mathrm{CONH}_{2}$ & - & 8.155 & 8.12 & 7.26 & 7.290 \\
\hline 6 & $\operatorname{Pr}$ & $\mathrm{Cl}$ & $\mathrm{CO}_{2} \mathrm{Me}$ & - & 7.638 & 8.287 & 6.337 & 6.975 \\
\hline 7 & $\operatorname{Pr}$ & $\mathrm{Cl}$ & COMe & - & 7.398 & 7.608 & 7.398 & 7.083 \\
\hline 8 & $\operatorname{Pr}$ & $\mathrm{CH}_{2} \mathrm{CH}_{2} \mathrm{CH}_{2} \mathrm{CH}_{2} \mathrm{C}(=0)$ & $\mathrm{H}$ & & 8.097 & 8.12 & 6.979 & 7.260 \\
\hline 9 & - & - & - & $\mathrm{H}_{3} \mathrm{C} \mathrm{C}_{\mathrm{C}}$ & 6.481 & 9 & 8.635 & \\
\hline 13 & - & - & - & Hydroxymethyl & 7.523 & 7.637 & 7.854 & 8.016 \\
\hline 14 & - & - & - & Ethoxymethyl & 8.301 & 8.157 & 7.699 & 7.587 \\
\hline 15 & - & - & - & Methoxymethyl & 8.398 & 7.727 & 7.69 & 7.675 \\
\hline 16 & - & - & $\mathrm{CONH}_{2}$ & Methoxymethyl & 9.222 & 8.879 & 8.398 & 7.860 \\
\hline 17 & - & - & $\mathrm{CONH}_{2}$ & Methyl & 8.699 & 8.037 & 8.301 & 7.308 \\
\hline 18 & - & - & $\mathrm{CONH}_{2}$ & Ethoxymethyl & 8.523 & 8.192 & 7.699 & 7.702 \\
\hline 19 & - & - & $\mathrm{CONH}_{2}$ & Chloro & 7.456 & 7.742 & 6.155 & 6.949 \\
\hline 20 & - & - & $\mathrm{CONH}_{2}$ & Ethyl & 8.886 & 8.419 & 8.155 & 8.176 \\
\hline 21 & - & - & $\mathrm{CONH}_{2}$ & 2-Fluoroethoxymethyl & 8.699 & 8.56 & 8.097 & 7.550 \\
\hline 22 & - & - & CONHMe & $\mathrm{H}$ & 8.097 & 8.528 & 8.155 & 8.151 \\
\hline 23 & - & - & CONHMe & Methyl & 8.398 & 8.528 & 8.301 & 7.500 \\
\hline
\end{tabular}

coverage with the target sequence. Therefore, in addition to sequence similarity, we used 7-TM architecture as another criterion. The amino acid sequence of $\mathrm{ET}_{\mathrm{A}}$ (427 amino acids) shows a significant percentage of identity with the thermostabilized adenosine $\mathrm{A}_{2 \mathrm{~A}}$ receptor [3PWH: 70/306 (23\%)] and the $\beta_{2}$-adrenergic receptor [3KJ6: 84/384 (22\%)]. Even though the target-template sequence similarity falls in the twilight region $(<30 \%)$, it is still possible to obtain a probable model of $\mathrm{ET}_{\mathrm{A}}$ based on these templates because all these proteins belong to the class A GPCR superfamily with a topology of seven transmembrane helices. Sequence-structure alignment has been reported to be superior to sequence-sequence alignment for the purpose of homology modeling; therefore, the former was used for our model building. The multiple sequence align- ment of the $\mathrm{ET}_{\mathrm{A}}$ sequence with $3 \mathrm{KJ} 6$ and $3 \mathrm{PWH}$ is shown in Figure 1, and conserved residues in the binding site region are shown in Supplementary Figure 1.

Several studies have reported that homology modeling based on multiple templates improves the quality of the modeled proteins, including $\mathrm{GPCR}^{[18-21]}$. Therefore, in this study we used multiple templates to generate the $\mathrm{ET}_{\mathrm{A}}$ model. Ten models were generated based on the human adenosine $\mathrm{A}_{2 \mathrm{~A}}$ Receptor (3PWH) and the $\beta_{2}$-Adrenergic Receptor (3KJ6) using the multiple templates protocol of modeller 9.10 software (Accelrys Inc, San Diego, CA, USA). Loop refinements were carried out using Prime software (Schrodinger, LLC, New York, NY, USA). The modeled proteins were energy minimized using the OPLS 2005 force-field. 
3PWH A|PDBID|CHAIN|SEQUENCE 3KJ6 A | PDBID | CHAIN | SEQUENCE $s p|P \overline{2} 5101|$ EDNRA_HUMAN

3PWH_A | PDBID | CHAIN | SEQUENCE $3 \mathrm{KJ} 6$ A | PDBID | CHAIN | SEQUENCE sp | P $\overline{2} 5101 \mid$ |EDNRA_HUMAN

3PWH_A | PDBID | CHAIN | SEQUENCE 3KJ6_A | PDBID | CHAIN | SEQUENCE sp|P25101|EDNRA_HUMAN

3PWH A| PDBID|CHAIN | SEQUENCE $3 \mathrm{KJ} 6$ - A | PDBID | CHAIN | SEQUENCE sp | P2 5101 |EDNRA_HUMAN

3PWH A | PDBID | CHAIN | SEQUENCE 3KJ6_A | PDBID | CHAIN | SEQUENCE sp | P $\overline{2} 5101 \mid$ |EDNRA_HUMAN

3PWH A| PDBID | CHAIN | SEQUENCE 3KJ6 A|PDBID|CHAIN | SEQUENCE sp | P $\overline{2} 5101$ |EDNRA_HUMAN

3PWH A | PDBID | CHAIN | SEQUENCE $3 \mathrm{KJ} 6$ A | PDBID | CHAIN | SEQUENCE sp | $\bar{P} \overline{2} 5101 \mid$ EDNRA_HUMAN

3PWH_A | PDBID | CHAIN | SEQUENCE $3 \mathrm{KJ} 6$ A | PDBID | CHAIN | SEQUENCE $s p|P \overline{2} 5101|$ EDNRA_HUMAN

3PWH_A | PDBID | CHAIN | SEQUENCE $3 \mathrm{KJ} 6$ - A | PDBID|CHAIN | SEQUENCE sp| $\overline{2} \mathbf{2} 5101 \mid$ EDNRA_HUMAN

3PWH A | PDBID | CHAIN | SEQUENCE 3KJ6 ${ }^{-}$A | PDBID | CHAIN | SEQUENCE sp| P25101|EDNRA_HUMAN

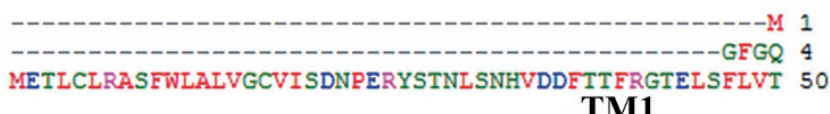

TM1

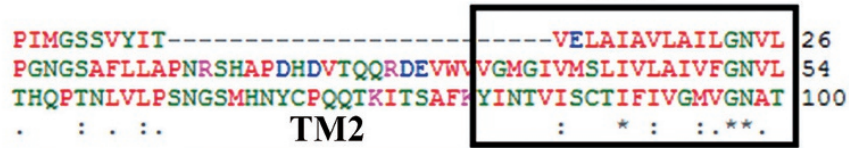

VC AAVWLNSNL NVTNYFVVSLAAADILVGVLIPF--AITISTGFCAAC 74 VI AIAKFERL TVTNYFITSLACADLVMGLA VPFGAAHILMRMNTFGN 104 LI I IYQNKCM NGPNALIASLALGDLIYVVI LPINVFKLLAGRWPFDH 150 TM3

----HGCI FIACFVLVLAQSSIFSLIAIA DRYIAIAIPLRYNGLVTGT 119 -----FWC FWTSIDVLCVTASIETLCVIA DRYFAITSPFKYQSLITKN 149 NDFGVFLC 2 FPFLQKSSVGITVLNLCALS DRYRAVASWSRVQGIGIPL 200

TM4

* :

RAAGI AICWVLSFAIGLTPMLGWNNCG KEGKNHSOGCGEGQVACLFE 169 KARVI LMVWIVSGLTSFLPIQMHWYRAT IQEAIN----CYAEETCCDFF 195 VTAIE VSIWILSFILAIPEAIGFVMVP F YRGEQ-HKTCMLNATSKFME 249

TM5

DVVPMNY VYFNFFACVLVPLILMLGVYI IFAAARRQLKQMES------ 213

TNQAY-- AIASSIVSFYVPLVIMVFVYS VVEEAKRQLQKIDKSEGRFH 242

FYQDVKD WLFGFYFCMPLVCTAIFYTLM CEMLNRRNGSLRIA----- 293

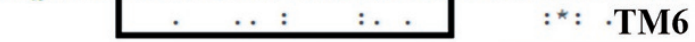

-QPLPGE----------RARSTLQKEVHAAKSAAI IAGLFALCWLPLHI 251 VQNLSQVEQDGRTGHGLRRSSKFCLKEHKALK LGI IMGTFTLCWLPFFI 292 ----------------LSEHLKQRREVAK VFCLVVIFALCWFPLHL $\$ 24$

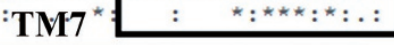

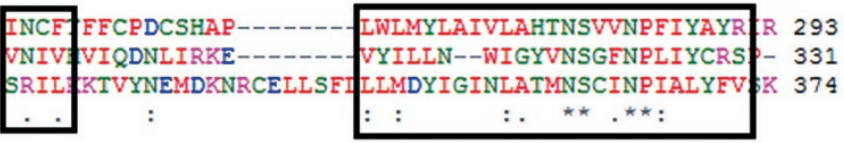

EFRQTFRKIIRSHVLRQQ-----EPFKAAAAHHHHHHHHHH--------- 329 DFRIAFQELICLRRSSLK-----AYGNGYSSNGNTGEQSG---------- 366 KFKNCFQSCLCCCCYQSKSLMTSVPMNGTSIQWKNHDQNNHNTDRSSHKD 424

$.^{\star}:{ }^{\star}: .: \quad: \quad:$ : : : : . :

$---$

$---$

SMN 427

Figure 1. Multiple structure sequence alignment between template crystal structures (3PWH and $3 \mathrm{KJ} 6)$ and the $\mathrm{ET}_{\mathrm{A}}$ sequence. In the sequences, an asterisk $(*)$ indicates an identical or conserved residue, a colon (:) indicates conserved substitutions, and a period (.) indicates semi-conserved substitutions.

\section{Validation of the predicted structure}

The overall stereo-chemical qualities of the ten generated models were assessed by PROCHECK (Hinxton, Cambridge, United Kindgom). One model was selected based on the best Ramachandran plot characteristics. The Ramachandran plot of the best model showed $81.6 \%$ of the residues in the most favorable region, $15.1 \%$ in the additional allowed region, $2.0 \%$ in the generously allowed region and $1.3 \%$ in the disallowed region. These results revealed that the majority of the amino acids are in a phi/psi distribution that is consistent with a right-handed a-helix and suggested that the model is reliable and of good quality. The G-factors, indicating the quality of the covalent, dihedral and overall bond angles, were -0.92 , -1.96 , and -1.28 , respectively. The overall main-chain and sidechain parameters, as evaluated by PROCHECK, were all very favorable. The Ramachandran plot characteristics confirmed the quality of the predicted model. The model selected was again subjected to MD simulation for further refinement of the structure.

\section{Molecular dynamics simulations}

Molecular dynamics can be used to explain protein structurefunction problems, such as folding, conformational flexibility and structural stability. In the simulations, we monitored the backbone atoms and the Ca-helix of the modeled protein. The RMSD values of the modeled structure $\left(\mathrm{ET}_{\mathrm{A}}\right)$ and $1 \mathrm{ZV} 0\left(\mathrm{AT}_{1} \mathrm{R}\right)$ protein backbone atoms were plotted as a time-dependent function of the MD simulation. The results support our modeled structure; they show constant RMSD after 25 ns of the simulation process for $\mathrm{ET}_{\mathrm{A}}$, and there is less deviation in the RMSD for $\mathrm{AT}_{1} \mathrm{R}$ after $6 \mathrm{~ns}$. The time dependence of the RMSD $(\AA)$ of the backbone atoms of the modeled protein $\left(\mathrm{ET}_{\mathrm{A}}\right)$ and the $1 \mathrm{ZV} 0\left(\mathrm{AT}_{1} \mathrm{R}\right)$ protein over the course of $30 \mathrm{~ns}$ of simulation is shown in Figures 2A and 2B. The graph clearly indicates 

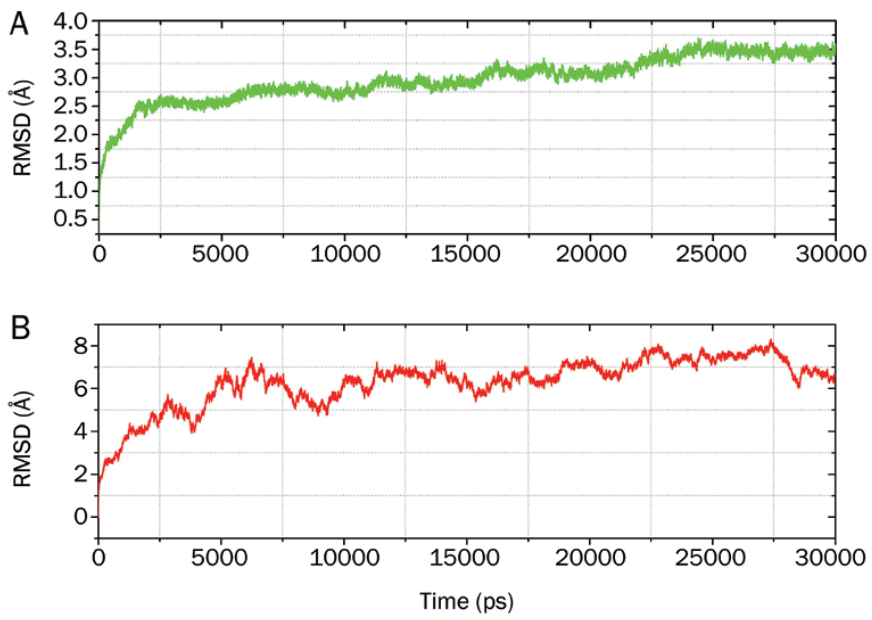

Figure 2. The RMSD of backbone atoms of the $E_{A}(A)$ and $A T_{1} R$ proteins $(B)$ from a 30 ns MD run.

that there is a change in the RMSD from $1.0 \AA$ to $3.0 \AA$ in the $\mathrm{ET}_{\mathrm{A}}$ homology model during the first $20 \mathrm{~ns}$, but after $20 \mathrm{~ns}$, the RMSD reaches a plateau. The RMSD values of the backbone atoms in the system tend to converge after $25 \mathrm{~ns}$, showing fluctuations of approximately $0.5 \AA$. The low RMSD and the simulation time indicate that, as expected, the 3D structural model of $\mathrm{ET}_{\mathrm{A}}$ represents a stable folding conformation. The RMSD of the $\mathrm{AT}_{1} \mathrm{R}$ protein was also analyzed; there was a constant deviation of the RMSD within $2 \AA$ after $4 \mathrm{~ns}$. This result confirms that the theoretical 3D structure of the $\mathrm{AT}_{1} \mathrm{R}$ protein (Pdb id: 1ZV0) is good enough for further study.

\section{Prediction and comparison of the active sites of $\mathrm{AT}_{1} \mathrm{R}$ and $\mathrm{ET}_{\mathrm{A}}$}

Taking into account the structural flexibility of the GPCR protein, we first evaluated the active sites of the modeled proteins in terms of shape, sterics, and electronic properties. From the contact scores $\left(0.956\right.$ for $\mathrm{AT}_{1} \mathrm{R}$ and 0.923 for $\left.\mathrm{ET}_{\mathrm{A}}\right)$, the strength of van der Waals contacts with the receptors also emerged; this is an important feature of each active site. The exposure and enclosure values are measures of the degree of opening of an active site to the solvent; these values are almost the same in both proteins (Table 2). However, the value of don/ acc is much less in $\mathrm{AT}_{1} \mathrm{R}$ compared to that in $\mathrm{ET}_{\mathrm{A}}$. This finding reveals that the intensities of hydrogen bond donor and acceptor regions are lower in $\mathrm{AT}_{1} \mathrm{R}$. The overall scores (site score) are almost the same in both of the proteins. This result

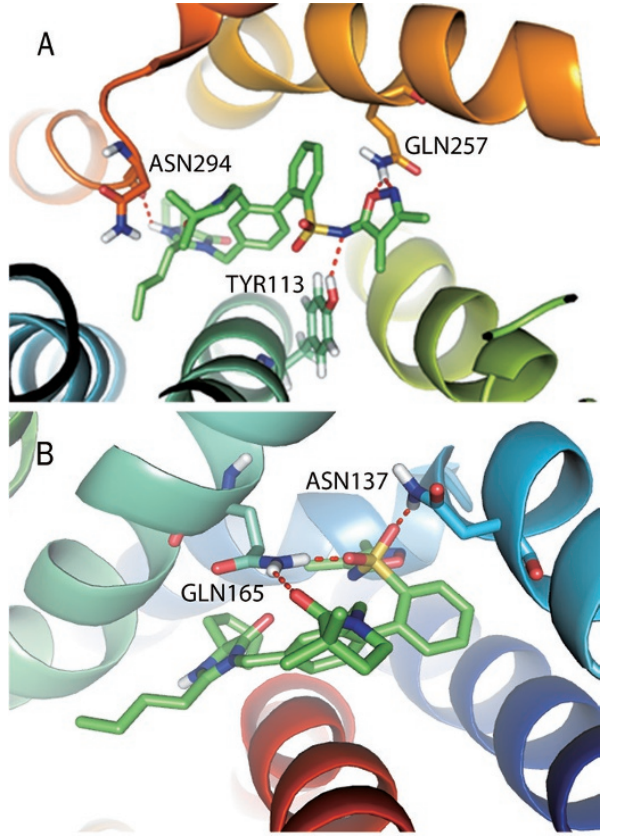

Figure 3. Binding modes of $A T_{1} R(A)$ and $E T_{A}(B)$ with the dual inhibitor BMS-248360.

provides further information regarding the active sites of the $\mathrm{AT}_{1} \mathrm{R}$ and $\mathrm{ET}_{\mathrm{A}}$ proteins and will facilitate the design of potent dual inhibitors.

\section{QM/MM docking of $A T_{1} R$ and $E_{A}$ with the dual inhibitor BMS-} 248360

A QM/MM docking study was performed with BMS-248360, a dual $\mathrm{AT}_{1} \mathrm{R}$ and $\mathrm{ET}_{\mathrm{A}}$ inhibitor, to further optimize the protein structures (Figures $3 \mathrm{~A}$ and $3 \mathrm{~B}$ ). N1 and $\mathrm{O} 2$ from oxazole form a hydrogen bond with the $-\mathrm{NH}_{2}$ group of $\mathrm{Gln} 257$ of $\mathrm{AT}_{1} \mathrm{R}$, and $\mathrm{N} 4$ near the oxosulfane oxide forms a hydrogen bond with the $-\mathrm{OH}$ group of Tyr113. Two benzene rings of BMS-248360 form П-П stacking with Phe204, Phe249, Tyr253, and His256, respectively. In $\mathrm{ET}_{\mathrm{A}}, \mathrm{O} 1$, and $\mathrm{O} 3$ from the oxosulfane oxide form hydrogen bonds with the $-\mathrm{NH}_{2}$ groups of Gln165 and $-\mathrm{NH}_{2}$ group of Asn137, respectively. O5 from 3,3-dimethylpyrrolidin-2-one forms a hydrogen bond with the $-\mathrm{NH}_{2}$ region of $\mathrm{Gln} 165$.

The binding free energy was also calculated using the MM/ GBSA approach for the proteins in complex with BMS-248360; the free energy was $-121.44 \mathrm{kcal} / \mathrm{mol}$ for $\mathrm{AT}_{1} \mathrm{R}$ and -120.21

Table 2. Comparison of active site of $A T_{1} R$ and $E_{A}$ protein using SiteMap (Schrodinger, LLC).

\begin{tabular}{lccccccccc}
\hline Protein & Site score & Size & Volume & Exposure & Enclosure & Contact & Phobic & Philic & Don/acc \\
\hline $\mathrm{AT}_{1} \mathrm{R}$ & 1.063 & 310 & 1117.837 & 0.597 & 0.753 & 0.956 & 1.081 & 0.904 & 0.654 \\
$\mathrm{ET}_{\mathrm{A}}$ & 1.114 & 322 & 1061.242 & 0.580 & 0.756 & 0.923 & 1.347 & 0.652 & 1.087 \\
\hline
\end{tabular}

Exposure/enclosure, properties measuring the degree of opening of active site to the solvent; contact, measure of site point interaction via vdW contacts; don/acc, property related to the sizes and intensities of $\mathrm{H}$-bond and acceptor regions; SiteScore: an overall score based on previous properties. 
Table 3. Relative binding free energies ( $\mathrm{kcal} / \mathrm{mol}$ ) between wild and mutant $\mathrm{ET}_{\mathrm{A}} / \mathrm{BMS}-248360$ and $\mathrm{AT}_{1} \mathrm{R} / \mathrm{BMS}-248360$ complex.

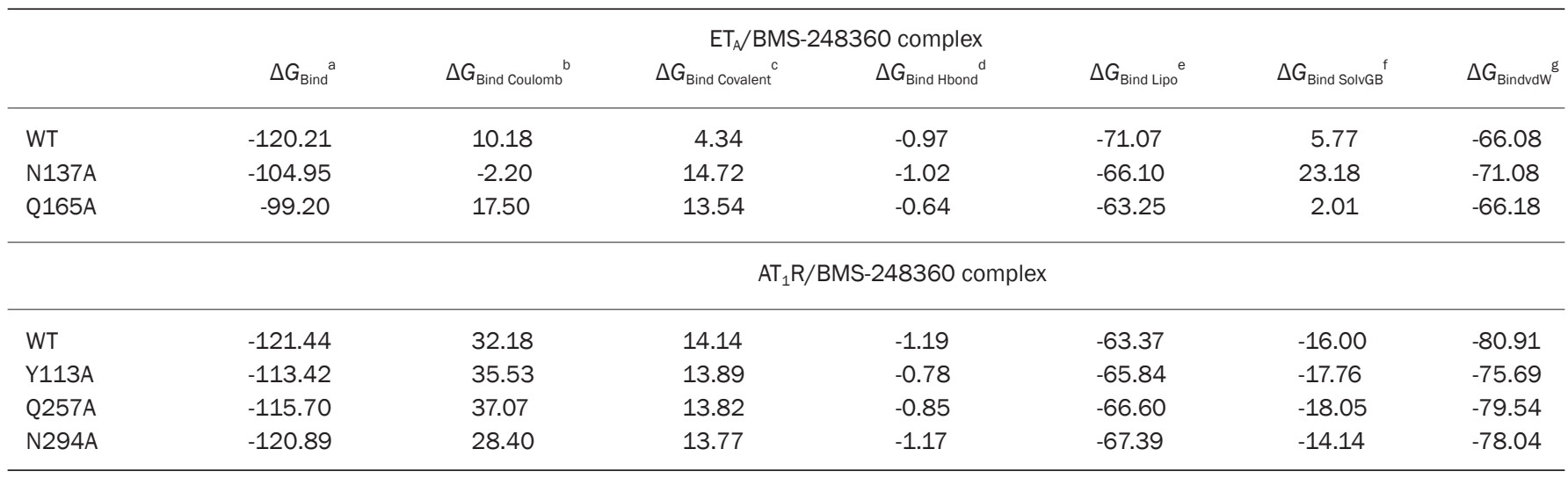

WT, Wild Type. ${ }^{a}$ MMGBSA free energy of binding; ${ }^{b}$ Contribution to the MMGBSA free energy of binding from the Coulomb energy; ${ }^{\circ}$ Contribution to the MMGBSA free energy of binding from covalent binding; ${ }^{\mathrm{d} C o n t r i b u t i o n}$ to the MMGBSA free energy of binding from hydrogen bonding; ${ }^{\mathrm{e}} \mathrm{Contribution}$ to the MMGBSA free energy of binding from lipophillic binding; ${ }^{\mathrm{f}}$ Contribution to the MMGBSA free energy of binding from the van der Waals energy; ${ }^{e}$ Contribution to the MMGBSA free energy of binding from the generalized Born electrostatic solvation energy.

$\mathrm{kcal} / \mathrm{mol}$ for $\mathrm{ET}_{\mathrm{A}}$. To explore the role of important amino acid residues in the ligand-protein interaction, we applied a computational mutagenesis (alanine scanning) to replace these residues with alanines. The results from our energetic analysis of the mutant complexes are shown in Table 3. In the $\mathrm{ET}_{\mathrm{A}} /$ BMS-248360 complex, the N137A and Q165A mutations were not favorable for $\Delta G_{\text {bind }}$, increased this parameter from -120.21 $\mathrm{kcal} / \mathrm{mol}$ to $-104.95 \mathrm{kcal} / \mathrm{mol}$ and $-99.20 \mathrm{kcal} / \mathrm{mol}$, respectively. The mutation increased the $\Delta G_{\text {Bind Covalent, the } \Delta G_{\text {Bind }}}$ Lipo and the $\Delta G_{\text {Bind SolvGB }}$ by $10.38 \mathrm{kcal} / \mathrm{mol}, 4.97 \mathrm{kcal} / \mathrm{mol}$ and $17.409 \mathrm{kcal} / \mathrm{mol}$, respectively. However, the $\Delta G_{\text {Bind Coulomb, the }}$ $\Delta G_{\text {Bind Hbond, }}$ and the $\Delta G_{\text {BindvdW }}$ were lower in the N137A mutant by $12.37 \mathrm{kcal} / \mathrm{mol}, 0.05 \mathrm{kcal} / \mathrm{mol}$ and $4.996 \mathrm{kcal} / \mathrm{mol}$, respectively. For the Q165A mutant, the $\Delta G_{\text {Bind Coulomb, the } \Delta G_{\text {Bind Covalent }}}$ the $\Delta G_{\text {Bind Hbond }}$ and the $\Delta G_{\text {Bind Lipo }}$ were increased, but the $\Delta G_{\text {Bind }}$ SolvGB and the $\Delta G_{\text {BindvdW }}$ were slightly decreased. This finding shows that N137 and Q165 are important residues for ligand binding. In the $\mathrm{AT}_{1} \mathrm{R} / \mathrm{BMS}-248360$ complex, the $\mathrm{Y} 113 \mathrm{~A}$, Q257A, and N294A mutations are not favorable for the $\Delta G_{\text {bind, }}$

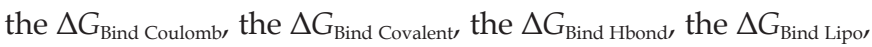
the $\Delta G_{\text {Bind SolvGB }}$, and the $\Delta G_{\text {BindvdW, }}$, based on our energetic analysis, but the N294A mutant slightly reduced the $\Delta G_{\text {Bind Coulomb }}$

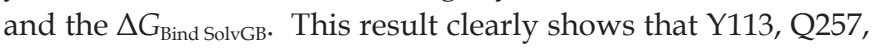
and N294 are important residues for ligand binding.

Glide extra-precision docking (XP), quantum polarized ligand docking and molecular mechanics-generalized born surface area (MM/GBSA) rescoring

To study the molecular basis of interactions between the imidazole compound series and $\mathrm{AT}_{1} \mathrm{R}$ and $\mathrm{ET}_{\mathrm{A}}$ and to analyze the affinity of this binding, all the ligands were docked into the active site using Glide XP (Table 4 and Table 5). The correlation between experimentally determined biological activity and the binding free energy was 0.291 for $\mathrm{AT}_{1} \mathrm{R}$ (Supplementary Figure 2) and 0.232 for $\mathrm{ET}_{\mathrm{A}}$ (Supplementary Figure 3). Because XP docking predicts a very low correlation between
Table 4. Docking and MM/GBSA free energy calculation result of imidazole series against $A T_{1} R$.

\begin{tabular}{|c|c|c|c|c|c|}
\hline $\begin{array}{l}\text { Com- } \\
\text { pound } \\
\text { № }\end{array}$ & $\begin{array}{c}\text { Docking } \\
\text { score }\end{array}$ & $\begin{array}{c}\text { Glide XP } \\
\text { Prime } \\
\mathrm{MM} / \mathrm{GBSA} \\
\Delta \mathrm{G}_{\text {bind }} \\
\text { (kcal/mol) }\end{array}$ & $\begin{array}{c}\text { Docking } \\
\text { score }\end{array}$ & $\begin{array}{c}\text { QPLD } \\
\text { Prime } \\
\mathrm{MM} / \mathrm{GBSA} \\
\Delta \mathrm{G}_{\text {bind }} \\
(\mathrm{kcal} / \mathrm{mol})\end{array}$ & $\begin{array}{c}\text { QM/MM } \\
\text { Energy } \\
\text { (kcal/mol) }\end{array}$ \\
\hline 1 & -5.26 & -75.56 & -6.89 & -64.13 & -2440.50 \\
\hline 2 & -6.34 & -76.61 & -7.05 & -74.00 & -2401.45 \\
\hline 3 & -6.29 & -81.32 & -6.77 & -85.62 & -2022.18 \\
\hline 4 & -5.96 & -73.55 & -6.03 & -72.35 & -2100.38 \\
\hline 5 & -7.05 & -77.10 & -6.74 & -78.74 & -2061.32 \\
\hline 6 & -6.44 & -75.23 & -5.83 & -73.97 & -2459.14 \\
\hline 7 & -6.09 & -74.83 & -6.17 & -73.06 & -2384.35 \\
\hline 8 & -5.32 & -79.96 & -6.23 & -72.43 & -2043.00 \\
\hline 9 & -7.38 & -67.69 & -7.07 & -76.72 & -2443.96 \\
\hline 10 & -5.99 & -77.08 & -5.68 & -86.48 & -2082.07 \\
\hline 11 & -6.32 & -77.41 & -5.64 & -78.47 & -2141.73 \\
\hline 12 & -5.77 & -80.75 & -6.56 & -79.96 & -2173.85 \\
\hline 13 & -5.09 & -75.18 & -5.67 & -76.67 & -2156.88 \\
\hline 14 & -6.08 & -58.90 & -6.46 & -86.97 & -2235.04 \\
\hline 15 & -6.46 & -87.60 & -6.67 & -88.34 & -2195.94 \\
\hline 16 & -6.25 & -91.41 & -7.20 & -92.19 & -2174.10 \\
\hline 17 & -6.34 & -67.28 & -6.56 & -88.70 & -2060.23 \\
\hline 18 & -6.62 & -89.29 & -7.09 & -87.73 & -2213.40 \\
\hline 19 & -6.23 & -50.66 & -5.84 & -74.39 & -2478.51 \\
\hline 20 & -6.06 & -90.77 & -7.11 & -89.02 & -2099.26 \\
\hline 21 & -6.04 & -86.25 & -6.68 & -88.56 & -2311.77 \\
\hline 22 & -6.15 & -82.19 & -5.99 & -88.61 & -2213.07 \\
\hline 23 & -5.72 & -84.53 & -6.20 & -88.61 & -2099.25 \\
\hline 24 & -6.08 & -72.01 & -6.34 & -78.40 & -2252.21 \\
\hline
\end{tabular}

experimental biological activity and the predicted binding free energy, we performed further study using QM-polarized docking. We assumed that this docking method would give 
Table 5. Docking and MM/GBSA free energy calculation result of imidazole series against $\mathrm{ET}_{\mathrm{A}}$.

\begin{tabular}{|c|c|c|c|c|c|}
\hline $\begin{array}{l}\text { Com- } \\
\text { pound } \\
\text { № }\end{array}$ & $\begin{array}{c}\text { Docking } \\
\text { score }\end{array}$ & $\begin{array}{c}\text { Glide XP } \\
\text { Prime } \\
\text { MM/GBSA } \\
\Delta G_{\text {bind }} \\
(\mathrm{kcal} / \mathrm{mol})\end{array}$ & $\begin{array}{c}\text { Docking } \\
\text { score }\end{array}$ & $\begin{array}{c}\text { QPLD } \\
\text { Prime } \\
\text { MM/GBSA } \\
\Delta G_{\text {bind }} \\
(\mathrm{kcal} / \mathrm{mol})\end{array}$ & $\begin{array}{c}\text { QM/MM } \\
\text { Energy } \\
\text { (kcal/mol) }\end{array}$ \\
\hline 1 & -9.91 & -69.01 & -7.15 & -63.59 & -2403.67 \\
\hline 2 & -10.64 & -79.62 & -7.15 & -74.74 & -2403.67 \\
\hline 3 & -10.81 & -78.41 & -6.13 & -71.39 & -2024.44 \\
\hline 4 & -9.87 & -65.88 & -7.01 & -73.10 & -2102.61 \\
\hline 5 & -9.96 & -82.48 & -6.35 & -83.52 & -2063.51 \\
\hline 6 & -9.92 & -70.35 & -6.87 & -67.40 & -2461.39 \\
\hline 7 & -9.01 & -79.18 & -6.22 & -75.28 & -2386.58 \\
\hline 8 & -8.89 & -72.03 & -6.18 & -70.50 & -2045.24 \\
\hline 9 & -6.95 & -95.25 & -7.99 & -93.49 & -2446.21 \\
\hline 10 & -8.31 & -88.90 & -6.37 & -88.83 & -2084.34 \\
\hline 11 & -6.96 & -79.07 & -7.56 & -86.17 & -2143.92 \\
\hline 12 & -7.41 & -84.99 & -7.45 & -87.80 & -2176.02 \\
\hline 13 & -8.02 & -81.05 & -8.04 & -86.36 & -2159.09 \\
\hline 14 & -8.43 & -78.41 & -6.60 & -84.83 & -2237.26 \\
\hline 15 & -7.53 & -76.52 & -6.47 & -85.79 & -2198.15 \\
\hline 16 & -9.80 & -88.43 & -6.97 & -89.33 & -2176.25 \\
\hline 17 & -9.03 & -88.99 & -6.56 & -88.72 & -2062.40 \\
\hline 18 & -8.14 & -78.33 & -7.39 & -83.73 & -2215.31 \\
\hline 19 & -7.21 & -85.58 & -7.00 & -66.75 & -2480.72 \\
\hline 20 & -7.50 & -86.65 & -7.01 & -75.99 & -2101.73 \\
\hline 21 & -8.10 & -55.09 & -7.21 & -59.67 & -2314.04 \\
\hline 22 & -7.89 & -85.64 & -7.43 & -87.66 & -2215.26 \\
\hline 23 & -7.75 & -88.68 & -6.55 & -88.97 & -2101.50 \\
\hline 24 & -8.10 & -80.69 & -6.81 & -90.30 & -2254.40 \\
\hline
\end{tabular}

a more accurate prediction of the electrostatic interactions ${ }^{[46]}$, which help to increase the docking accuracy. All 24 imidazole series compounds were docked inside the active sites of $\mathrm{AT}_{1} \mathrm{R}$ and $\mathrm{ET}_{\mathrm{A}}$ using QPLD. The binding mode of inhibitors predicted using Glide XP docking was almost identical to that predicted by QPLD. The top five poses per molecule were submitted for rescoring using the MM/GBSA process. The correlations between the MM/GBSA result and experimental activity (0.603 and 0.508 for $\mathrm{AT}_{1} \mathrm{R}$ and $\mathrm{ET}_{\mathrm{A}}$ (Figure 4), respectively) were better than the correlations between the docking scores and the experimental activity. The MM/GBSA rescoring of QPLD showed better correlation with the biological experimental activity than the MM/GBSA scoring from Glide $\mathrm{XP}$ docking calculation. Therefore, this docking method gives more accurate treatment of electrostatic interactions, which helps to improve the docking accuracy. We used the QPLD docked ligand conformation to generate the 3D-QSAR model.

\section{Analysis of 3D-QSAR validation}

Reliable predictions can only come from statistically valid QSAR models. Several statistical parameters can be used to evaluate the robustness of a QSAR model, including leave-nout cross validation of the training set $\left(R^{2}\right)$, leave-n-out cross
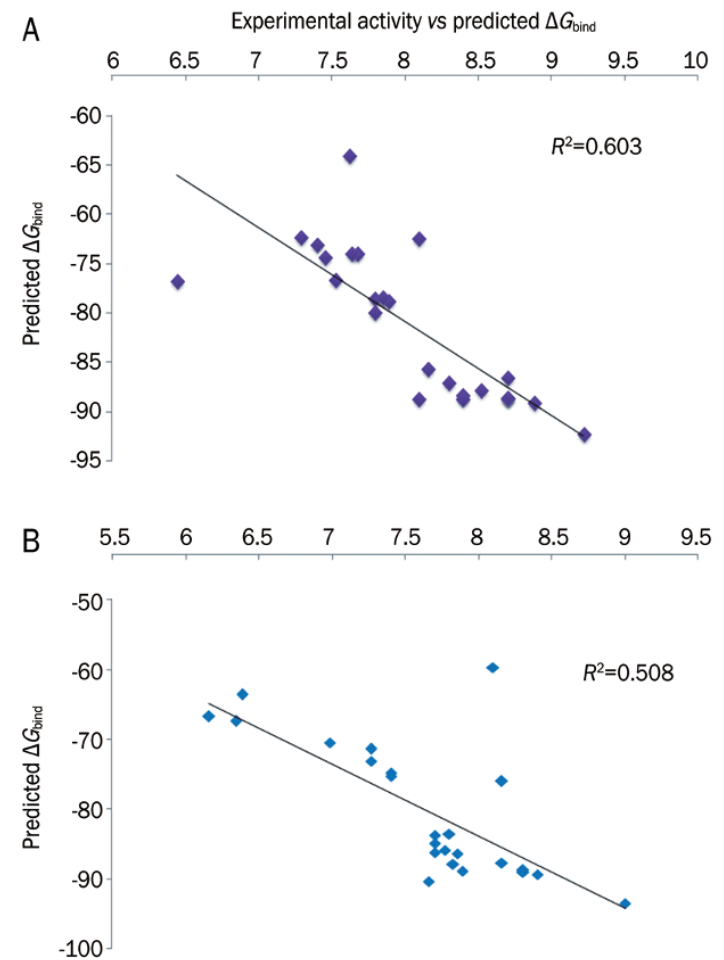

Experimental $p K_{i}$

Figure 4. Experimental activity vs predicted $\Delta G_{\text {bind }}$ of $A T_{1} R(A)$ and $E T_{A}(B)$ from the QPLD pose.

validation of the test set $\left(Q^{2}\right)$, the standard deviation (SD), the Root Mean Square Error (RMSE), and the variance ratio $(F)$. High $R^{2}$ is an important condition for a predictive QSAR model. The best QSAR model will be chosen based on its predictive ability, so in addition to high $R^{2}$, the best model should also have high $Q^{2}$. For $\mathrm{AT}_{1} \mathrm{R}$, we obtained a good $R^{2}$ value for the training set (0.72), excellent predictive power with a $Q^{2}$ of 0.69 , an RMSE of 0.254 , a standard deviation (SD) of 0.38 , an $F$ variance ratio of 35.7 , a Pearson $R$ correlation (between the predicted and observed activity for the test set) of 0.85 , and an $r_{\text {pred }}^{2}$ of 0.66 . Plots of the predicted $v s$ actual $\mathrm{pKi}$ for the training and test sets are shown in Figure $5 \mathrm{~A}$. For $\mathrm{ET}_{\mathrm{A}}$, we obtained an $R^{2}$ value for the training set of 0.971 , excellent predictive power with a $Q^{2}$ of 0.84 , an RMSE of 0.11 , a SD of 0.04 , an $F$ variance ratio of 159.1, a Pearson $R$ correlation (predicted and observed activity for the test set) of 0.92 , and an $r_{\text {pred }}^{2}$ of 0.70. Plots of the predicted $v s$ actual $\mathrm{p} K_{\mathrm{i}}$ for the training and test sets are shown in Figure 5B.

\section{Analysis of 3D-QSAR model}

Additional insight into the inhibitory activity can be gained by visualizing the QSAR model in the context of the most and least active compounds. The contribution maps obtained from our result shows how 3D-QSAR methods can identify features that are important for the interaction between each ligand and its target protein. Such maps allow the identification of those positions that require a particular physicochemical property to enhance the bioactivity of a ligand. A pictorial representa- 

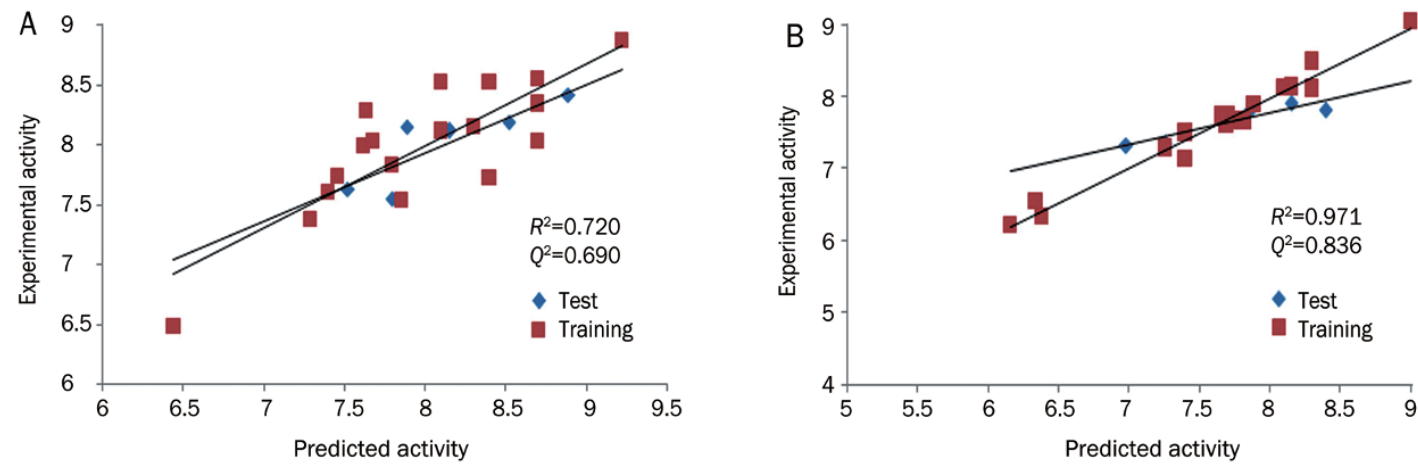

Figure 5. Graph of actual versus predicted $\mathrm{pK} \mathrm{i}_{\mathrm{i}}$ of the training set and the test set using the atom-based QSAR model from $\mathrm{PHASE}$ for $\mathrm{AT}{ }_{1} \mathrm{R}(\mathrm{A})$ and $\mathrm{ET} \mathrm{A}_{\mathrm{A}}(\mathrm{B})$.

tion of the contours generated for $A T_{1} R$ is shown in Figures $6 \mathrm{~A}-6 \mathrm{~B}$; the contours generated for $\mathrm{ET}_{\mathrm{A}}$ are shown in Figures $6 \mathrm{C}-6 \mathrm{D}$. In these representations, the blue cubes indicate favorable regions, while red cubes indicate unfavorable regions for activity.

Figures $6 \mathrm{~A}$ and $6 \mathrm{~B}\left(\mathrm{AT}_{1} \mathrm{R}\right)$ compares the most significant favorable and unfavorable features that arise when the QSAR model is applied to the most active compound (16) and the least active compound (9) for $\mathrm{AT}_{1} \mathrm{R}$ inhibition. In the context of compound 16, the blue cubes are observed near the (2,3-dimethylcyclopenta-1,3-dien-1-yl)sulfuramidous acid and the N17 region. However, a red cube is still observed near the ethyl group of the $\mathrm{H}$-imidazole region. In the context of the least active compound (9), red cubes are observed near N-(3,4-dimethyl-1,2-oxazol-5-yl)benzenesulfonamide, N17 of tetrahydro-H-benzimidazole and the trimethylpyrrolidinone region. However, blue cubes are still observed near the tetrahydro-H-benzimidazole region, which may be a result of the addition of cyclooctanone to the $\mathrm{H}$-imidazole region. The activity of the molecule is greatly influenced by the substitution of methoxymethyl group in $\mathrm{C} 4$ of the benzene ring. The further addition of cyclooctanone to the H-imidazole region
A

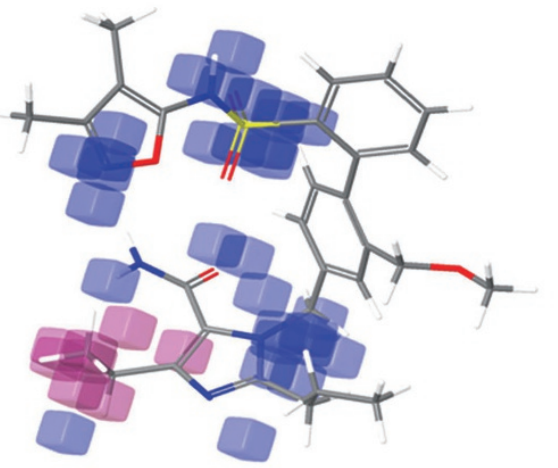

C

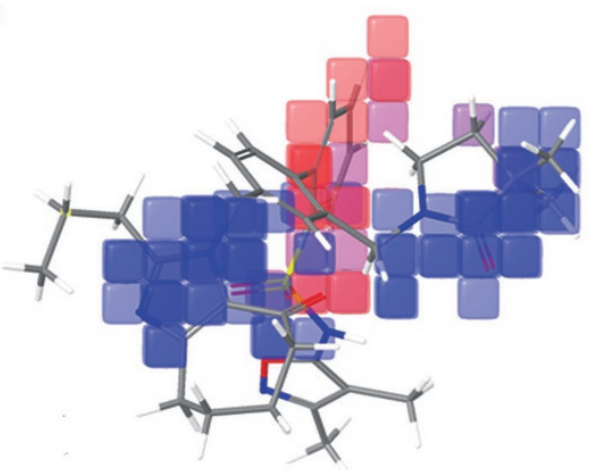

B

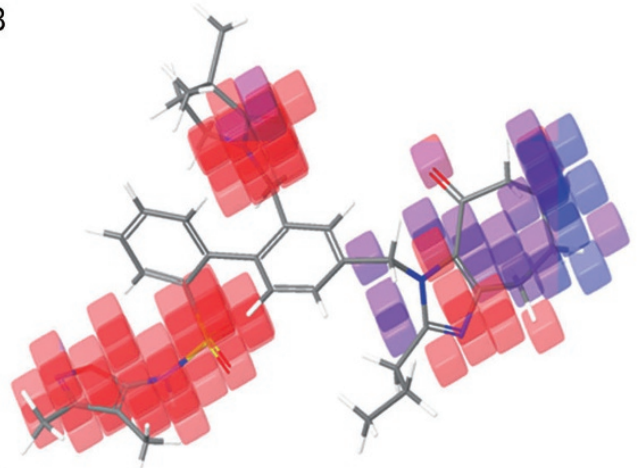

D

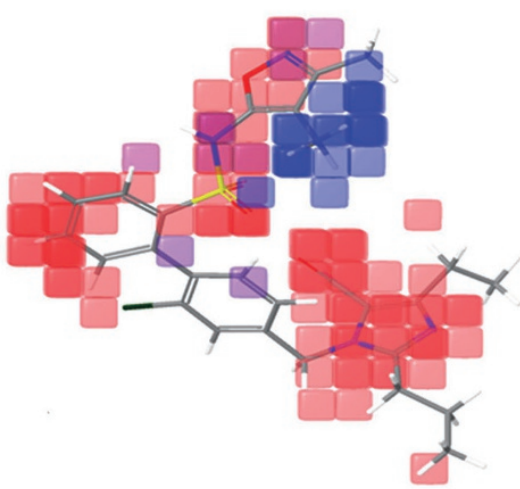

Figure 6. Pictorial representation of the cubes generated using the QSAR model. Blue areas indicate favorable regions, while red areas indicate unfavorable regions for the activity. The QSAR model visualized in the context most active compound, 16 (A), and the least active compound, 9 (B), against $A T_{1} R$. The QSAR model visualized in the context of the most active compound, 9 (C), and the least active compound 19 (D), against $A T_{1} R$. 
may increase the activity in the most active compound.

Figures 6C and 6D $\left(\mathrm{ET}_{\mathrm{A}}\right)$ compare the most significant favorable and unfavorable features that arise when the QSAR model is applied to the most active compound (9) and the least active compound (19) for $\mathrm{ET}_{\mathrm{A}}$ inhibition. In the context of compound 9, blue cubes are observed in the region of the pyrazole and the trimethylpyrrolidinone. However, red cubes are observed near the benzene ring. In the context of compound 19, red cubes are observed near the 5-[(aminooxy)methyl]-4-ethyl2-propyl-1H-imidazole benzene ring and in the (3,4-dimethyl1,2-oxazol-5-yl)sulfuramidous acid region. However, blue cubes are also observed in the two methyl groups of $\mathrm{N}-(3,4-$ dimethyl-1,2-oxazol-5-yl)benzenesulfonamide. This finding indicates that the substitution of cyclooctanone in the H-imidazole and trimethylpyrrolidinone increased the activity of the molecule.

From our 3D-QSAR study, we observed that the substitution of cyclooctanone and trimethylpyrrolidinone is important for the activity of the compound against the $\mathrm{ET}_{\mathrm{A}}$ protein. However, in the case of $\mathrm{AT}_{1} \mathrm{R}$, the substitutions of trimethylpyrrolidinone reduce the activity of the compounds, and the substitution of the methoxymethyl group on $\mathrm{R}_{4}$ influences the activity of the molecule. The addition of aminooxy methane and the ethyl group on H-imidazole also increases the activity. The sizes and intensities of the H-bond donor and acceptor region are comparatively small in $\mathrm{AT}_{1} \mathrm{R}$ compared to those in the $\mathrm{ET}_{\mathrm{A}}$ protein (Table 2). This difference may explain why the addition of trimethylpyrrolidinone reduces the activity against
$\mathrm{AT}_{1} \mathrm{R}$ protein but increases the activity against $\mathrm{ET}_{\mathrm{A}}$.

Binding mode analysis of the most active compound (compound 16) and the least active compound (compound 9) against $A T_{1} R$

Molecular docking studies were performed to understand the binding mode and mechanism of binding between the most active compound (16) (Figure 7A) and the least active compound (9) and $\mathrm{AT}_{1} \mathrm{R}$ (Figure $7 \mathrm{~B}$ ). To obtain information for further structure optimization, we used Quantum Polarized Ligand Docking. The $-\mathrm{C}=\mathrm{O}$ from $-\mathrm{CONH}_{2}\left(\mathrm{R}_{3}\right)$ of compound 16 forms a hydrogen bond with $\mathrm{N} 294$, and the $-\mathrm{NH}_{2}$ group from $-\mathrm{CONH}_{2}$ also forms two hydrogen bonds with $\mathrm{S} 115$ and D74, respectively. Two benzene rings from the major scaffold have $\Pi-\Pi$ stacking with $\mathrm{H} 256$ and F249, respectively. The O1 from the oxosulfane oxide group of compound 9 forms a hydrogen bond with the $-\mathrm{OH}$ group of $\mathrm{Y} 113$ of $\mathrm{AT}_{1} \mathrm{R}$, and $\mathrm{N} 1$ from the imidazole near cycloheptanone interacts with the - $\mathrm{COOH}$ group of D74 of $\mathrm{AT}_{1} \mathrm{R}$. Dimethyl-dihydro-oxazole and the benzene ring near oxosulfane oxide have $\Pi-\Pi$ stacking with $\mathrm{H} 256$ and F204, respectively. Molecular docking also reveals that the substitution of $-\mathrm{CONH}_{2}$ forms a greater number of hydrogen bonds, which may enhance the activity of the molecule, and the substitution of trimethylpyrrolidinone may reduce the activity of the molecule. This result further confirms that the substituted bulky group (trimethylpyrrolidinone) in $\mathrm{R}_{4}$ cannot fit inside the active site of $\mathrm{AT}_{1} \mathrm{R}$, and therefore, the activity of the molecule decreases.

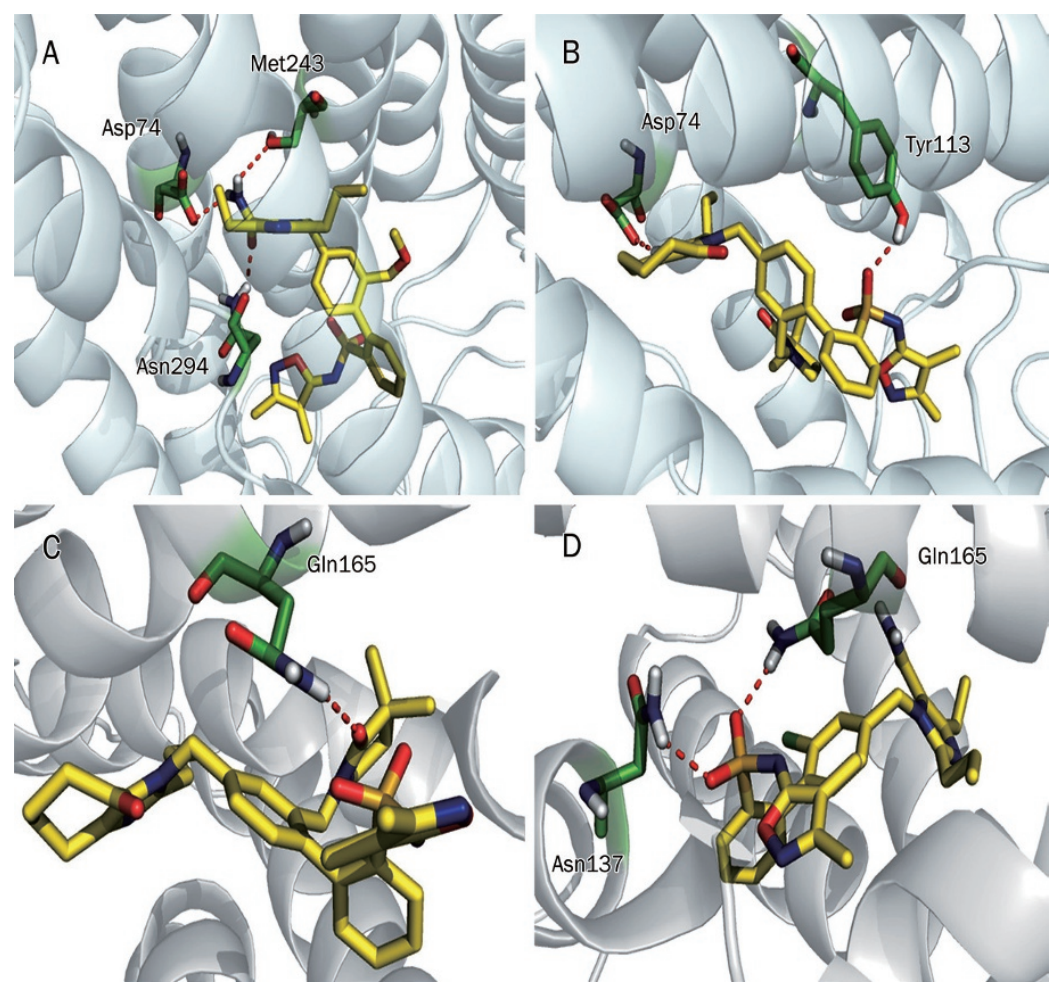

Figure 7. The binding mode of $A T_{1} R$ and its inhibitors. (A) The most active compound, 16 , and (B) the least active compound, 9 . The binding mode of $\mathrm{ET}_{\mathrm{A}}$ and its inhibitors (C) the least active compound, 19, and (D) the most active compound, 19. 
Binding mode analysis of the most active compound (compound 9) and the least active compound (compound 19) against $\mathrm{ET}_{\mathrm{A}}$

In the most active compound against $\mathrm{ET}_{\mathrm{A}}$ (9) (Figure 7C), the O5 from 3,3-dimethylpyrrolidin-2-one (R4) forms a hydrogen bond with the $\mathrm{NH}_{2}$ of $\mathrm{Q} 165$ in $\mathrm{ET}_{\mathrm{A}}$. Imidazole participates in $\Pi-\Pi$ stacking with W240. In the case of the least active compound against $\mathrm{ET}_{\mathrm{A}}$ (19) (Figure 7D), $\mathrm{O} 1$ and $\mathrm{O} 2$ of the oxosulfane oxide group form hydrogen bonds with the $\mathrm{NH}_{2}$ of Gln165 and the $\mathrm{NH}_{2}$ of Asn137, respectively. From this docking result, we also observed that there was $\Pi-\Pi$ stacking for the most active compound and that this may play an important role in the activity of the molecule. We also observed that the substitution of trimethylpyrrolidinone does not affect the activity of the molecule, and this substituted compound is able to fit inside the active site of $\mathrm{ET}_{\mathrm{A}}$. This docking study also revealed that the substitution of trimethylpyrrolidinone $\left(\mathrm{R}_{4}\right)$ may influence the activity of the molecule.

\section{Pharmacophore- and structure-based screening}

Pharmacophore models containing five sites were generated using the selected molecules for this study (24 imidazole series compounds $)^{[15]}$, which were reported as dual inhibitors of both $\mathrm{AT}_{1} \mathrm{R}$ and $\mathrm{ET}_{\mathrm{A}}$. The common hypothetical pharmacophores with three and four features were rejected for the study based on the molecule occupancy of the pharmacophoric features. The best two hypothetical pharmacophores, AARRR and AARRH, were selected based on the scoring function for further pharmacophore-based screening (Figure 8). The selected hypothetical pharmacophore consists of two hydrogen bond acceptors (A) and three aromatic rings (R) for the first hypothesis, and the second hypothetical pharmacophore consists of two hydrogen bond acceptors (A), two aromatic rings (R) and one hydrophobic group $(\mathrm{H})$.

A database search retrieved all the positive hits and filtered out the inactive compounds. The interpretation of how the pharmacophore maps onto the positive hits may provide insight into the structural requirements for dual inhibition of $\mathrm{AT}_{1} \mathrm{R}$ and $\mathrm{ET}_{\mathrm{A}}$ and can act as a guide for the further refinement of the molecules to design a better molecule with good absorption, distribution, metabolism, and excretion (ADME) properties. The generated pharmacophore model screened against the ChemBridge chemical databases of 511,324 compounds. The compounds that possessed fitness scores higher than 1.500 (2873 compounds) were subjected to high-throughput virtual screening (HTVS) against $\mathrm{AT}_{1} \mathrm{R}$ and $\mathrm{ET}_{\mathrm{A}}$ separately. After HTVS, SP docking and XP docking, which are considered to be more precise modes of docking simulation, were performed. We identified 46 compounds targeting $\mathrm{AT}_{1} \mathrm{R}$ and 33 compounds targeting $\mathrm{ET}_{\mathrm{A}}$ that were able to effectively bind to their active site through this docking procedure. Further, we re-docked (using XP flexible docking) these 46 compounds targeting $\mathrm{ET}_{\mathrm{A}}$ and 33 compounds targeting $\mathrm{AT}_{1} \mathrm{R}$; this approach identified 17 compounds that are able to effectively bind to the active site of both proteins. The selection of compounds was based on the glide score, glide energy, emodel, binding
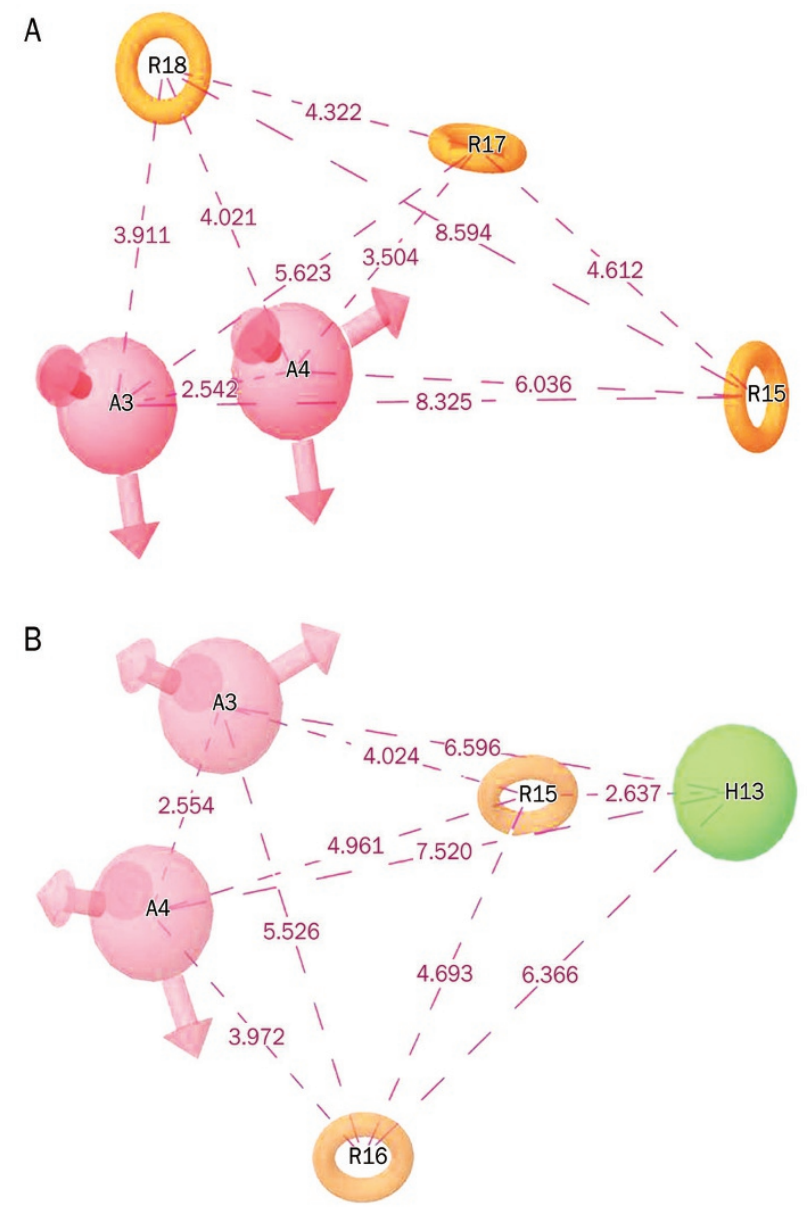

Figure 8. The two top-ranked pharmacophore models with the pharmacophore distance $(\AA)$.

free energy and conformation of binding, which are similar to those of the known compounds. It has been reported that ensemble rescoring ${ }^{[53-55]}$ increases the percentage of correctly docked poses. Therefore, we used ensemble rescoring to identify the potential dual inhibitors. Henriksen et al also applied ensemble rescoring in identifying lead molecules using virtual screening ${ }^{[56]}$. They found that 19 out of 41 predicted compounds were active in an enzyme assay and that 14 of these compounds were active in subsequent whole cell assays.

Next, we subjected these 17 dual-inhibitory compounds to quantum polarized ligand docking, which we found to be more accurate for this study, and we identified 5 compounds that bind very effectively and close to the binding mode of the most active known compounds with good docking score and good binding free energy. The 2D structures of the five identified compounds are shown in Figure 9. The binding mode and docking scores are shown in Table 6 and Table 7. The binding modes of the five lead compounds inside the binding pocket of $\mathrm{AT}_{1} \mathrm{R}$ and $\mathrm{ET}_{\mathrm{A}}$ are shown in Supplementary Figures 4 and 5 , respectively. 


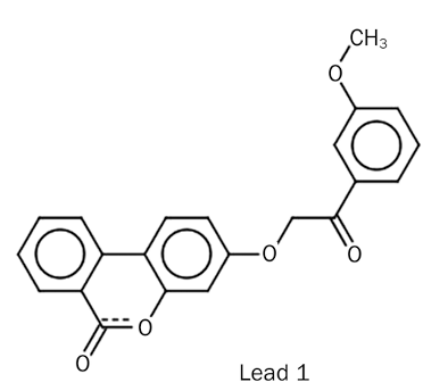

Lead 1

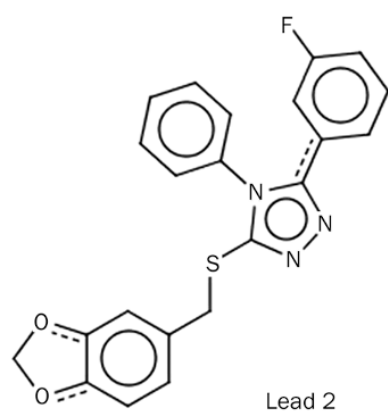

Lead 2<smiles>O=C(CSC1CC(=O)N(c2ccc(Br)cc2)C1=O)Nc1ccc2ccccc2c1</smiles>

Lead 4<smiles>CCOC(=O)c1ccc(N2C(=O)C[C@H](SCC(=O)Nc3ccc4ccccc4c3)C2=O)cc1</smiles>

Lead 3

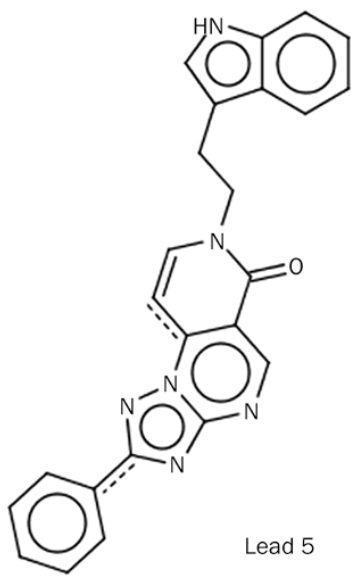

Figure 9. The chemical structure of five leading molecules that may be potential dual inhibitors of $A T_{1} R$ and $E T_{A}$.

Table 6. Docking score and predicted activity of $\mathrm{ET}_{\mathrm{A}}$ protein. Predicted activity was calculated using the equation $Y=-9.470 x-5.020$, where $Y$ is the activity and $x$ is the $\Delta G_{\text {bind }}$. The equation was derived from the correlation equation of experimentally predicted activity and $\Delta G_{\text {bind }}$ of the compounds studied for QSAR analysis.

\begin{tabular}{lllll}
\hline $\begin{array}{c}\text { Compound } \\
\text { name }\end{array}$ & $\begin{array}{l}\text { Docking } \\
\text { score }\end{array}$ & $\begin{array}{c}\text { QM/MM } \\
\text { Energy } \\
\text { (kcal/mol) }\end{array}$ & $\begin{array}{c}\text { MM/GBSA } \\
(\mathrm{kcal} / \mathrm{mol})\end{array}$ & $\begin{array}{c}\text { Predicted } \\
\text { activity }\end{array}$ \\
\hline Lead 1 & -7.52 & -1216.96 & -78.18 & 7.45 \\
Lead 2 & -9.31 & -1651.27 & -76.15 & 7.25 \\
Lead 3 & -7.51 & -1839.31 & -88.57 & 8.47 \\
Lead 4 & -7.96 & -4134.87 & -84.92 & 8.11 \\
Lead 5 & -7.42 & -1321.34 & -71.75 & 6.83 \\
\hline
\end{tabular}

\section{Enrichment of the virtual screening protocol}

In a virtual screening process, the best hypothesis or docking calculation should distinguish the active compounds from the inactive ones. A decoy set, composed of 27 known dual inhibitors of $\mathrm{AT}_{1} \mathrm{R}$ and $\mathrm{ET}_{\mathrm{A}}$ and 100 decoy molecules from Schrodinger, was used to validate whether the use of the hypothetical pharmacophores (AARRH and AARRR), VS, and QPLD could discriminate the active compounds from the inactive compounds. The result was analyzed using a set of parameters such as the hit list (Ht), number of active percent of yields $(\% \mathrm{Y})$, percent ratio of actives in the hit list $(\% \mathrm{~A})$, enrichment factor (E), false negatives, false positives, and goodness of hit score $(\mathrm{GH})$ (Supplementary Table 1 and 2$)^{[57,58]}$. We observed
Table 7. Docking score and predicted activity of $A T_{1} R$ protein. Predicted activity was calculated using the equation $Y=-10.26 x-1.717$, where $Y$ is the activity and $x$ is the $\Delta G_{\text {bind }}$. The equation was derived from the correlation equation of experimentally predicted activity and $\Delta G_{\text {bind }}$ of the compounds studied for QSAR analysis.

\begin{tabular}{lllll}
\hline $\begin{array}{l}\text { Compound } \\
\text { name }\end{array}$ & $\begin{array}{l}\text { Docking } \\
\text { score }\end{array}$ & $\begin{array}{c}\text { QM/MM } \\
\text { Energy } \\
(\mathrm{kcal} / \mathrm{mol})\end{array}$ & $\begin{array}{c}\text { MM/GBSA } \\
(\mathrm{kcal} / \mathrm{mol})\end{array}$ & $\begin{array}{r}\text { Predicted } \\
\text { activity }\end{array}$ \\
\hline Lead 1 & -8.00 & -1216.95 & -60.37 & 5.85 \\
Lead 2 & -5.98 & -1651.27 & -64.82 & 6.31 \\
Lead 3 & -7.85 & -1839.33 & -85.01 & 8.45 \\
Lead 4 & -7.32 & -4138.87 & -88.23 & 8.79 \\
Lead 5 & -7.30 & -1321.34 & -74.50 & 7.34 \\
\hline
\end{tabular}

that all the GH values were between 0.6 and 0.8 , which indicates that the quality of the pharmacophore models and VS are acceptable. Based on our overall validations, we can assume that both the pharmacophore hypothesis and the docking calculation were able to predict most of the compounds in the same order of magnitude and that it can discriminate the active inhibitors from the inactive or low-activity compounds. Because QPLD has better GH values, we assumed that this docking protocol would be able to discriminate the active inhibitors from the inactive ones. Therefore, we propose that our virtual screening protocol can effectively discriminate the most suitable dual inhibitors of $\mathrm{AT}_{1} \mathrm{R}$ and $\mathrm{ET}_{\mathrm{A}}$. 
Analysis of identified compounds using QSAR model generated against $\mathrm{AT}_{1} \mathrm{R}$

We superimposed our QSAR model generated on the most active compound with the five identified compounds (Supplementary Figure 6). In lead 1, blue cubes were observed on the $6 \mathrm{H}$-benzo[c]chromen-6-one regions of the compound, and the $-\mathrm{C}=\mathrm{O}$ from $6 \mathrm{H}$-benzo[c]chromen-6-one formed a hydrogen bond with Val179 of $\mathrm{AT}_{1} \mathrm{R}$. Therefore, this functional group may be important for the activity against $\mathrm{AT}_{1} \mathrm{R}$. In lead 2, blue cubes were observed near the triazole and the benzene ring, but unfortunately, there were no interactions in this region. In lead 3, blue cubes were observed on ethyl formate, and the benzene ring attached to it had $\Pi-\Pi$ stacking with Trp253 of $\mathrm{AT}_{1} \mathrm{R}$. Ethyl formate has a high electron-withdrawing capacity and may influence the activity of the molecule. In lead 4, the blue cubes were observed near the pyrrolidine-2,5-dione region, and $\mathrm{O} 11$ formed $\mathrm{H}$-bonds with Tyr113 of $\mathrm{AT}_{1} \mathrm{R}$. The bromobenzene near pyrrolidine-2,5-dione also formed П-П stacking with Trp253. In lead 5, blue cubes were observed on the indole, and the $-\mathrm{NH}$ from the indole formed a H-bond and $\Pi-\Pi$ stacking with Tyr292. Therefore, the indole of lead 5 may be an important functional group for the activity of the molecule.

Analysis of identified compounds using QSAR model generated against $\mathrm{ET}_{\mathrm{A}}$

In the context of lead 1, blue cubes were observed on methoxybenzene, and this benzene formed $\Pi-\Pi$ stacking with Tyr50 (Supplementary Figure 7). A hybrid of red cubes and blue cubes were observed near the $6 \mathrm{H}$-benzo[c]chromen-6-one. The $\mathrm{O}$ from cyclohexane formed an H-bond with Gln86 of $\mathrm{ET}_{\mathrm{A}}$, and the benzene ring formed $\Pi-\Pi$ stacking with Tyr186. Because $6 \mathrm{H}$-benzo[c]chromen-6-one influenced the activity of the leads against both $\mathrm{AT}_{1} \mathrm{R}$ and $\mathrm{ET}_{\mathrm{A}}$, this may be a particularly important substitution for the dual inhibitory activity. In lead 2 , blue cubes were observed on the benzodioxole group, and red cubes were observed on the fluorobenzene group. Therefore, the substitution of benzodioxole may be an important substitution for the activity against $\mathrm{ET}_{\mathrm{A}}$. In lead 3, blue cubes were observed on ethyl formate, but unfortunately, there was no interaction with this substitution. However, ethyl formate is an important substitution for the activity of this lead compound against $\mathrm{AT}_{1} \mathrm{R}$; the substitution of ethyl formate may be an important substitution for dual inhibitory activity. In lead 4, blue cubes were observed on naphthalene; this could be an important substitution for the activity against $\mathrm{ET}_{\mathrm{A}}$. In the context of lead 5, blue cubes were observed on the ethyl group, and a mix of red cubes and blue cubes was observed near the indole substitution. The $-\mathrm{NH}$ from the indole group formed an H-bond with Gln86 of $\mathrm{ET}_{\mathrm{A}}$. The indole group is an important substitution for both the proteins; thus, this substitution could be important for dual inhibitory activity.

\section{Conclusion}

In summary, a structurally reasonable and energetically reliable model of $\mathrm{ET}_{\mathrm{A}}$ was built using the multi-template homology modeling technique and a subsequent stepwise refinement procedure by molecular dynamics simulation; the known inhibitors were then docked into the active site of the initial model. With this refined $\mathrm{ET}_{\mathrm{A}}$ model and the structure of $\mathrm{AT}_{1} \mathrm{R}$, retrieved from PDB, we performed QPLD docking with the known dual inhibitor BMS-248360 to further optimize the model structure. We found that Tyr113, Gln257, and Asn294 from $\mathrm{AT}_{1} \mathrm{R}$ formed hydrogen bonds with BMS-248360 and that Asn137 and Gln165 from $\mathrm{ET}_{\mathrm{A}}$ formed hydrogen bonds with BMS-248360. Further, we subjected these structures to Glide XP docking and QPLD with dataset compounds. The QPLD docking result showed better correlation with the experimental activity for both the proteins. We generated a 3D-QSAR model from this conformation, with good correlations of $R^{2}=0.72$ and $Q^{2}=0.69$ for $\mathrm{AT}_{1} \mathrm{R}$ and $R^{2}=0.97$ and $Q^{2}=0.84$ for $\mathrm{ET}_{\mathrm{A}}$. Further, the visualization of the 3D-QSAR model in the context of the molecules under study provided details of the relationship between structure and activity; our model therefore provides explicit indications for the design of better analogues. The substitution of methoxymethyl and cyclooctanone may increase the activity of the molecule against the $A_{1} R$ protein. In the case of the $\mathrm{ET}_{\mathrm{A}}$ protein, the substitution of cyclohexone and trimethylpyrrolidinone is important for the activity of the compound. From this study, we also observed that the addition of trimethylpyrrolidinone to compound 9 significantly reduced its activity against $\mathrm{AT}_{1} \mathrm{R}$ but significantly increased its activity against $\mathrm{ET}_{\mathrm{A}}$ due to the larger size and greater intensities of the H-bond donor and acceptor regions. Pharmacophore-based screening, followed by subsequent Glide SP, XP, and QPLD calculation, identified five potential leading molecules that could be potential dual inhibitors for both $\mathrm{AT}_{1} \mathrm{R}$ and $\mathrm{ET}_{\mathrm{A}}$. The results from this study may provide some insights into the development of novel potent dual $\mathrm{ET}_{\mathrm{A}}$ and $\mathrm{AT}_{1} \mathrm{R}$ antagonists.

\section{Acknowledgements}

This work was supported by the University Grant Commission (UGC), Government of India [Grant № 37-12/2009 (SR)]. KDS gratefully acknowledges CSIR for providing the Senior Research Fellowship (SRF). The authors thank Dr M RAVIKUMAR (Application Scientist from Schrödinger, Bangalore) for the detailed discussion and suggestions. The suggestions from the anonymous reviewers of this manuscript are cordially appreciated.

\section{Author contribution}

Karthikeyan MUTHUSAMY designed research; Khuraijam Dhanachandra SINGH performed research; Karthikeyan MUTHUSAMY and Khuraijam Dhanachandra SINGH contributed new analytical tools and reagents; Karthikeyan MUTHUSAMY and Khuraijam Dhanachandra SINGH analyzed data; Karthikeyan MUTHUSAMY and Khuraijam Dhanachandra SINGH wrote the paper.

\section{Supplementary information}

Supplementary information is available at the Acta Pharmaco- 
logica Sinica website.

\section{References}

1 Ceolotto G, Papparella I, Bortoluzzi A, Strapazzon G, Ragazzo F, Bratti $\mathrm{P}$, et al. Interplay between miR-155, $\mathrm{AT}_{1} \mathrm{R}$ A1166C polymorphism, and $\mathrm{AT}_{1} \mathrm{R}$ expression in young untreated hypertensives. Am J Hypertens 2011; 24: 241-6.

2 Papadopoulos DP, Papademetriou V. Targeting angiotensin II type I receptors to reduce the risk of stroke in patients with hypertension. Expert Opin Ther Targets 2006; 10: 231-7.

3 Gradman AH. Role of angiotensin II type 1 receptor antagonists in the treatment of hypertension in patients aged >or $=65$ years. Drugs Aging 2009; 26: 751-67.

4 Wojciak-Stothard B. New drug targets for pulmonary hypertension: Rho GTPases in pulmonary vascular remodelling. Postgraduate Med J 2008; 84: 348-53.

5 Kingman M, Ruggiero R, Torres F Ambrisentan. An endothelin receptor type A - selective endothelin receptor antagonist, for the treatment of pulmonary arterial hypertension. Expert Opin Pharmacother 2009; 10: $1847-58$

6 Barst RJ. A review of pulmonary arterial hypertension: role of ambrisentan. Vasc Health Risk Manag 2007; 3: 11-22.

7 van den Meiracker AH, Admiraal PJ, Janssen JA, Kroodsma JM, de Ronde WA, Boomsma F, et al. Hemodynamic and biochemical effects of the $\mathrm{AT}_{1}$ receptor antagonist irbesartan in hypertension. Hypertension 1995; 25: 22-9.

8 Lee RJ, Brunner HR. Clinical experience with angiotensin II receptor antagonists. J Hum Hypertens 1993; 7: S33-S36.

9 Yanagisawa M, Kurihara H, Kimura S, Tomobe Y, Kobayashi M, Mitsui $\mathrm{Y}$, et al. A novel potent vasoconstrictor peptide produced by vascular endothelial cells. Nature (Lond) 1988; 332: 411-5.

10 Krum H, Viskoper RJ, Lacourciere Y, Budde M, Charlton V. The effect of an endothelin-receptor antagonist, bosentan, on blood pressure in patients with essential hypertension. N Engl J Med 1998; 338: 784-90.

11 Murugesan N, Gu Z, Fadnis L, Tellew JE, Baska RA, Yang Y, et al. Dual angiotensin II and endothelin A receptor antagonists: synthesis of 2'-substituted N-3-isoxazolyl biphenylsulfonamides with improved potency and pharmacokinetics. J Med Chem 2005; 48: 171-9.

12 Kowala MC, Murugesan N, Tellew J, Carlson K, Monshizadegan H, Ryan $\mathrm{C}$, et al. Novel dual action $\mathrm{AT}_{1}$ and $\mathrm{ET}_{\mathrm{A}}$ receptor antagonists reduce blood pressure in experimental hypertension. J Pharmacol Exp Ther 2004; 309: 275-84.

13 Imai T, Hirata Y, Emori T, Yanagisawa M, Masaki T, Marumo F. Induction of endothelin-1 gene by angiotensin and vasopressin in endothelial cells. Hypertension 1992; 19: 753-7.

14 Chua BH, Chua CC, Diglio CA, Siu BB. Regulation of endothelin-1 mRNA by angiotensin II in rat heart endothelial cells. Biochim Biophys Acta 1993; 1178: 201-6.

15 Tellew JE, Baska RAF, Beyer SM, Carlson KE, Cornelius LA, Fadnis L, et al. Discovery of 4'-[(Imidazol-1-yl)methyl]biphenyl-2-sulfonamides as dual endothelin/angiotensin II receptor antagonists. Bioorg Med Chem Lett 2003; 13: 1093-6.

16 Larkin MA, Blackshields G, Brown NP, Chenna R, McGettigan $\mathrm{PA}, \mathrm{McWilliam} \mathrm{H}$, et al. Clustal $\mathrm{W}$ and Clustal $\mathrm{X}$ version 2.0. Bioinformatics 2007; 23: 2947-8.

17 Henikoff S, Henikoff JG. Amino-acid substitution matrices from protein blocks. Proc Natl Acad Sci U S A 1992; 89: 10915-9.

18 Yarnitzky T, Levit A, Niv MY. Homology modeling of G-protein-coupled receptors with $X$ ray structures on the rise. Curr Opin Drug Discov Devel 2010; 13: 317-25.
19 Larsson P, Wallner B, Lindahl E, Elofsson A. Using multiple templates to improve quality of homology models in automated homology modeling. Protein Sci 2008; 17: 990-1002.

20 Sokkar P, Mohandass S, Ramachandran M. Multiple templates-based homology modeling enhances structure quality of $\mathrm{AT}_{1}$ receptor: validation by molecular dynamics and antagonist docking. J Mol Model 201; 17: 1565-77.

21 Fanelli F, De Benedetti PG. Update 1 of computational modeling approaches to structure-function analysis of $\mathrm{G}$ protein-coupled receptors. Chem Rev 2011; 111: PR438-535.

22 Eswar N, Webb B, Marti-Renom MA, Madhusudhan MS, Eramian $\mathrm{D}$, Shen MY, et al. Comparative protein structure modeling using modeller. Curr Protoc Bioinformatics. Hoboken (New Jersey): John Wiley \& Sons, Inc; 2002.

23 Mart-Renom MA, Stuart AC, Fiser AS, Sanchez R, Melo F, Sali A. Comparative protein structure modeling of genes and genomes. Annu Rev Biophys Biomol Struct 2000; 29: 291-325.

24 Sali A, Blundell TL. Comparative protein modelling by satisfaction of spatial restraints. J Mol Biol 1993; 234: 779-815.

25 Fiser A, Do RKG, Sali A. Modeling of loops in protein structures. Protein Sci 2000; 9: 1753-73.

26 Laskowski RA, MacArthur MW, Thornton JM. Validation of protein models derived from experiment. Curr Opin Struct Biol 1998; 8: 6319.

27 Prime, version 3.0, Schrödinger, LLC, New York, NY, 2011.

28 Maestro, version 9.2, Schrödinger, LLC, New York, NY, 2011.

29 Laskowski RA, MacArthur MW, Moss DS, Thornton JM. PROCHECK: a program to check the stereochemical quality of protein structures. J Appl Cryst 1993; 26: 283-91.

30 Clément M, Martin SS, Beaulieu ME, Chamberland C, Lavigne P, Leduc $\mathrm{R}$, et al. Determining the environment of the ligand binding pocket of the human angiotensin II type I (hAT1) receptor using the methionine proximity assay. J Biol Chem 2005; 280: 27121-9.

31 Jorgensen WL, Maxwell DS, Tirado-Rives J. Development and testing of the OPLS all-atom force field on conformational energetics and properties of organic liquids. J Am Chem Soc 1996; 118: 11225-36

32 Kaminski GA, Friesner RA, Tirado-Rives J, Jorgensen WL. Evaluation and reparametrization of the OPLS-AA force field for proteins via comparison with accurate quantum chemical calculations on peptides. J Phys Chem B 2001; 105: 6474-87.

33 Braganza LF, Worcester DL. Hydrostatic pressure induces hydrocarbon chain interdigitation in single-component phospholipid bilayers. Biochemistry 1986; 25: 2591-6.

34 Faraldo-Gómez JD, Smith GR, Sansom MS. Setting up and optimization of membrane protein simulations. Eur Biophys J 2002; 31: 217-27.

35 Schlegel B, Sippl W, Höltje HD. Molecular dynamics simulations of bovine rhodopsin: influence of protonation states and different membrane-mimicking environments. J Mol Model 2005; 12: 49-64.

36 Jorgensen WL, Madura JD. Temperature and size dependence for Monte Carlo simulations of TIP4P water. Mol Phys 1985; 56: 138192.

37 Singh K, Kirubakaran P, Nagarajan S, Sakkiah S, Muthusamy K, Velmurgan D, et al. Homology modeling, molecular dynamics, e-pharmacophore mapping and docking study of Chikungunya virus nsP2 protease. J Mol Model 2012; 18: 39-51.

38 Isberg V, Balle T, Sander T, Jorgensen FS, Gloriam DE. G protein- and agonist-bound serotonin $5-\mathrm{HT}_{2 \mathrm{~A}}$ receptor model activated by steered molecular dynamics simulations. J Chem Inf Model 2011; 51: 31525.

39 Glide, version 5.7, Schrödinger, LLC, New York, NY, 2011. 
40 SiteMap, version 2.5, Schrödinger, LLC, New York, NY, 2011.

41 LigPrep, version 2.5, Schrödinger, LLC, New York, NY, 2011.

42 Schrödinger Suite 2011 QM-Polarized Ligand Docking protocol; Glide version 5.7, Schrödinger, LLC, New York, NY, 2011; Jaguar version 7.8, Schrödinger, LLC, New York, NY, 2011; QSite version 5.7, Schrödinger, LLC, New York, NY, 2011.

43 Cho AE, Guallar V, Berne BJ, Friesner R. Importance of accurate charges in molecular docking: Quantum mechanical/molecular mechanical (QM/MM) approach. J Comput Chem 2005; 26: 915-31.

44 Jaguar, version 7.8, Schrödinger, LLC, New York, NY, 2011.

45 Impact, version 5.5, Schrödinger, LLC, New York, NY, 2005

46 Yang Y, Qin J, Liu H, Yao X. Molecular dynamics simulation, free energy calculation and structure-based 3D-QSAR studies of B-RAF kinase inhibitors. J Chem Inf Model 2012; 51: 680-92.

47 Massova I, Kollman PA. Computational alanine scanning to probe protein-protein interactions: a novel approach to evaluate binding free energies. J Am Chem Soc 1999; 121: 8133-43

48 Moreira IS, Fernandes PA, Ramos MJ. Computational alanine scanning mutagenesis - an improved methodological approach. J Comput Chem 2007; 28: 644-54.

49 Afroz Alam M, Naik P. Molecular modelling evaluation of the cytotoxic activity of podophyllotoxin analogues. J Comput Aided Mol Des 2009; 23: 209-25.

50 Dhanachandra Singh Kh, Karthikeyan M, Kirubakaran P, Nagamani S. Pharmacophore filtering and 3D-QSAR in the discovery of new JAK2 inhibitors. J Mol Graph Model 2011; 30: 186-97.

51 Phase, version 3.3, Schrödinger, LLC, New York, NY, 2011.

52 Dixon S, Smondyrev A, Knoll E, Rao S, Shaw D, Friesner R. PHASE: a new engine for pharmacophore perception, 3D QSAR model development, and 3D database screening: 1 . Methodology and preliminary results. J Comput Aided Mol Des 2006; 20: 647-71.

53 Guimarães CR, Cardozo M. MM-GB/SA rescoring of docking poses in structure-based lead optimization. J Chem Inf Model 2008; 48: 958-70.

54 Guimarães CR. MM-GB/SA rescoring of docking poses. Methods Mol Biol 2012; 819: 255-68.

55 Henriksen ST, Liu J, Estiu G, Oltvai ZN, Wiest O. Identification of novel bacterial histidine biosynthesis inhibitors using docking, ensemble rescoring, and whole-cell assays. Bioorg Med Chem 2010; 18: 514856.

56 Thompson DC, Humblet C, Joseph-McCarthy D. Investigation of MMPBSA rescoring of docking poses. J Chem Inf Model 2008; 48: 108191.

57 Ahmed A, Choo H, Cho YS, Park WK, Pae AN. Identification of novel serotonin $2 \mathrm{C}$ receptor ligands by sequential virtual screening. Bioorg Med Chem 2009; 17: 4559-68.

58 Sakkiah S, Thangapandian S, John S, Lee KW. Pharmacophore based virtual screening, molecular docking studies to design potent heat shock protein 90 inhibitors. Eur J Med Chem 2011; 46: 2937-47. 